\title{
Smooth crack-free targets for nuclear applications produced by molecular plating
}

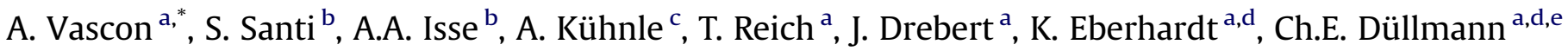 \\ a Institute of Nuclear Chemistry, Johannes Gutenberg University Mainz, 55099 Mainz, Germany \\ ${ }^{\mathrm{b}}$ Department of Chemical Sciences, University of Padova, 35131 Padova, Italy \\ c Institute of Physical Chemistry, Johannes Gutenberg University Mainz, 55099 Mainz, Germany \\ d SHE Chemistry Research Section, Helmholtz Institute Mainz, 55099 Mainz, Germany \\ e SHE Chemistry Department, GSI Helmholtzzentrum für Schwerionenforschung GmbH, 64291 Darmstadt, Germany
}

\section{A R T I C L E I N F O}

\section{Article history:}

Received 31 October 2012

Received in revised form

8 February 2013

Accepted 4 March 2013

Available online 14 March 2013

Keywords:

Smooth crack-free targets

Molecular plating

Neodymium

$\gamma$-ray spectroscopy

Atomic force microscopy (AFM)

$\mathrm{X}$-ray photoelectron spectroscopy (XPS)

\begin{abstract}
A B S T R A C T
The production process of smooth and crack-free targets by means of constant current electrolysis in organic media, commonly known as molecular plating, was optimized. Using a Nd salt, i.e., $\left[\mathrm{Nd}\left(\mathrm{NO}_{3}\right)_{3} \cdot 6 \mathrm{H}_{2} \mathrm{O}\right]$, as model electrolyte several constant current density electrolysis experiments were carried out to investigate the effects of different parameters, namely the plating solvent (isopropanol and isobutanol mixed together, pyridine, and $N, N$-dimethylformamide), the electrolyte concentration $(0.11,0.22,0.44 \mathrm{mM})$, the applied current density $\left(0.17,0.3,0.7\right.$, and $\left.1.3 \mathrm{~mA} / \mathrm{cm}^{2}\right)$, and the surface roughness of the deposition substrates (12 and $24 \mathrm{~nm}$ ). Different environments (air and $\mathrm{Ar}$ ) were used to dry the samples and the effects on the produced layers were investigated. The obtained deposits were characterized using $\gamma$-ray spectroscopy for determining Nd deposition yields, X-ray photoelectron spectroscopy for chemical analysis of the produced surfaces, radiographic imaging for surface homogeneity inspection, atomic force microscopy for surface roughness evaluation, and scanning electron microscopy for surface morphology investigation. The results allowed identifying the optimum parameters for the production of smooth and crack-free targets by means of molecular plating. The smoothest layers, which had an average RMS roughness of ca. $20 \mathrm{~nm}$ and showed no cracks, were obtained using $0.22 \mathrm{mM}\left[\mathrm{Nd}\left(\mathrm{NO}_{3}\right)_{3} \cdot 6 \mathrm{H}_{2} \mathrm{O}\right]$ plated from $\mathrm{N}, \mathrm{N}$-dimethylformamide at current densities in the range of $0.3-0.7 \mathrm{~mA} / \mathrm{cm}^{2}$ on the smoothest deposition substrate available.
\end{abstract}

c 2013 Elsevier B.V. All rights reserved.

\section{Introduction}

Targets are an essential component in experimental nuclear science as a source of stationary nuclei, e.g., for atomic and nuclear spectroscopy or nuclear reaction studies [1-3]. Generally, targets should be chemically pure, uniform, homogeneous, crack-free over the area of interest, and well adherent to the deposition substrate. Among the several techniques available to prepare thin layers to be used as nuclear targets [4-8], molecular plating (MP) is one of the most effective and most successfully applied ones $[9,10]$. This technique, based on the electrodeposition of the element of interest from an organic medium either in the constant current or in the constant voltage mode, is usually chosen because of the possibility to quickly produce deposits of acceptable uniformity and adherence with quantitative yield. Recently Garcia et al. [11,12] applied polymer assisted deposition (PAD), developed by Jia et al. [13] as an alternative method to prepare thin films of metal oxides,

\footnotetext{
* Correspondence to: Institute of Nuclear Chemistry, Johannes Gutenberg University Mainz, Fritz-Strassmann-Weg 2, D-55128 Mainz, Germany. Tel.: +496131 39 26510; fax: +4961313920811.

E-mail address: vascon@uni-mainz.de (A. Vascon).
}

to produce nuclear targets. PAD has been claimed to yield targets with better uniformity and homogeneity than MP. In the present work, we demonstrate that thanks to an improved understanding of the electrochemistry of MP and to more extensive surface science investigations [14,15], which showed that the roughness of the films depends on variables like deposition substrate and electrolyte concentration, targets prepared via MP can be also very uniform and homogeneous, as smooth and crack-free layers can be produced.

\section{Experiments and results}

\subsection{Deposition cell}

The cell used for the MPs is characterized by a central PEEK body where the electrolytic solution is inserted [14]. The anode and the cathode are both Ti blocks covered by a Pd foil and a Ti foil, respectively. Each of the two electrodes has an area of $9 \mathrm{~cm}^{2}$. The distance between the electrodes is $2.8 \mathrm{~cm}$. The cathode was designed to be easily removed from the cell and to be used for liquid AFM investigations. Fig. 1 shows the cathode of the cell: a Ti 


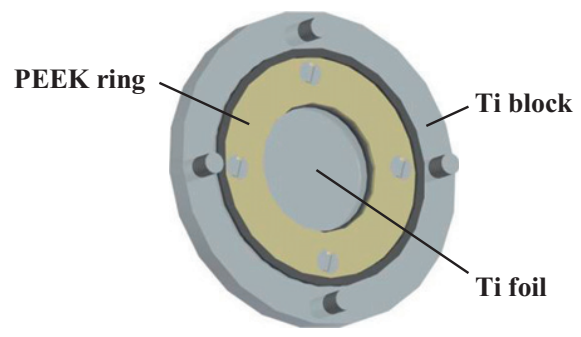

Fig. 1. 3D drawing of the cathode assembly: a Ti block covered with a circular Ti foil fixed with a PEEK ring. The cathode assembly is part of the molecular plating cell.

block covered with a circular Ti foil fixed with a PEEK ring. A constant temperature of $16{ }^{\circ} \mathrm{C}$ was maintained in the cell by water-cooling the Ti blocks, which were in physical contact with the electrodes.

\subsection{Solvents used for molecular plating}

Different solvents were used to perform the MPs: isopropanol, isobutanol, pyridine, and $N, N$-dimethylformamide (DMF). Isopropanol and isobutanol were always used together as a mixture (3\% isopropanol, $97 \%$ isobutanol), hereafter referred to as IP+IB. Table 1 shows some physical properties of relevance of the used solvents [16].

The data reported in Table 1 show DMF to have the highest boiling point, conductivity, and relative permittivity; its viscosity is instead the lowest one. Pyridine has the lowest relative permittivity, a viscosity approaching that of DMF and a boiling point quite close to the one of the IP+IB mixture. The physical properties of the IP + IB mixture can be approximated to those of pure isobutanol, which makes up $97 \%$ by volume of the mixture. IP+IB has the highest viscosity and the lowest conductivity.

\subsection{Deposition substrates}

The deposition substrates used in the present work are listed in Table 2 . Their surface roughnesses, evaluated by AFM (see Section 2.5 in [14]) after the cleaning procedure, are reported as average root mean square values $(\overline{R M S})$. To facilitate comparison of the results reported here and previously in [14], we keep the labelling of our substrate types as in [14].

Ti3 was a circular $50 \mu$ m-thick Ti foil cut from a bigger foil (Goodfellow). Ti5 was produced by coating a $300-\mu \mathrm{m}$ thick, mechanically polished Si wafer with $100 \mathrm{~nm}$ metallic Ti. The substrates used for deposition in the cell had different surface roughnesses: larger, corresponding to a more defective surface (Ti3, Fig. 2a), and smaller, corresponding to a less defective surface (Ti5, Fig. 2b).

\subsection{Molecular plating at constant current density}

Before any deposition, both the anode (Pd foil) and the cathode (Ti foil) were cleaned with $6 \mathrm{M} \mathrm{HCl}(1 \times 3 \mathrm{~mL}$ washing), water $(3 \times 3 \mathrm{~mL}$ washings), and isopropanol ( $1 \times 3 \mathrm{~mL}$ washing). Only Ti5 substrates were cleaned using $\mathrm{HCl}$ with a lower concentration (i.e., $0.6 \mathrm{M}$ ) in order to avoid corrosion-induced increase in surface roughness, as verified in [14]. For the MPs, 0.338, 0.675, and $1.350 \mathrm{~g}$ of [Nd( $\left.\left(\mathrm{NO}_{3}\right) 3 \cdot 6 \mathrm{H}_{2} \mathrm{O}\right]$ were dissolved in $20 \mathrm{~mL} 0.1 \mathrm{M} \mathrm{HNO}_{3}$ to give final solutions of three different concentrations. From each solution an aliquot of $100 \mu \mathrm{L}$ was added to a mixture of $1 \mathrm{~mL}$ isopropanol (Fisher Chemical) and $34 \mathrm{~mL}$ isobutanol (Applichem), or to $35 \mathrm{~mL}$ of pyridine (Merck) or DMF (Merck), finally yielding three different solutions of $\mathrm{Nd}^{3+}$ in the cell; these are referred to as low concentration (LC, $0.11 \mathrm{mM}$ ), medium concentration (MC, $0.22 \mathrm{mM}$ ), and high concentration ( $\mathrm{HC}, 0.44 \mathrm{mM})$. In the cell the concentration of $\mathrm{HNO}_{3}$ was $0.3 \mathrm{mM}$. The plating solutions were stirred by means of a quartz tip ultrasonic stirrer (Bandelin Sonopuls HD 2070) operated at 30\%
Table 1

Some physical properties (at $25^{\circ} \mathrm{C}$ ) of the solvents used for the MPs [16].

\begin{tabular}{lrlll}
\hline Solvent & $\begin{array}{l}\text { Bp } \\
\left({ }^{\circ} \mathbf{C}\right)\end{array}$ & $\begin{array}{l}\text { Viscosity } \\
(\mathbf{C P})\end{array}$ & $\begin{array}{l}\text { Conductivity } \\
(\mathbf{S m} / \mathbf{c m})\end{array}$ & $\begin{array}{l}\text { Relative } \\
\text { permittivity }\end{array}$ \\
\hline $\begin{array}{l}\text { Isopropanol (IP) } \\
\text { Isobutanol (IB) }\end{array}$ & 82.2 & 2.044 & $6 \times 10^{-8}$ & 19.9 \\
Pyridine & 107.7 & 3.910 & $2 \times 10^{-8}$ & 17.9 \\
$\begin{array}{l}\boldsymbol{N}, \boldsymbol{N} \text {-dimethylformamide } \\
\quad(\mathbf{D M F})\end{array}$ & 115.3 & 0.884 & $4 \times 10^{-8}$ & 12.9 \\
$\quad 153.0$ & 0.802 & $6 \times 10^{-8}$ & 36.7 \\
\hline
\end{tabular}

Table 2

Deposition substrates used for the MPs and their average surface roughness values $(\overline{R M S})$ determined by AFM.

\begin{tabular}{llc}
\hline Substrate type & Production technique & $\overline{\text { RMS }(\mathbf{n m})}$ \\
\hline Ti3 & Rolling & $24 \pm 7$ \\
Ti5 & Magnetron sputtering & $12.8 \pm 0.7$ \\
\hline
\end{tabular}

power pulse. MP experiments were always carried out for $3 \mathrm{~h}$ by applying a constant current of $6 \mathrm{~mA}$, corresponding to a current density of $0.7 \mathrm{~mA} / \mathrm{cm}^{2}$. Three-hours long MPs were also performed by testing different constant currents, i.e., $1.5,3$, or $12 \mathrm{~mA}$. The corresponding current densities were $0.17,0.3$, and $1.3 \mathrm{~mA} / \mathrm{cm}^{2}$ (Table 3).

\subsection{Atomic force microscopy (AFM) studies}

\subsubsection{Experiments}

The surface roughness of the deposited layers, i.e., the measure of the texture of a surface quantified by the vertical deviations of a real surface from its ideal planar form, was investigated by using atomic force microscopy (AFM) (MFP 3D Asylum Research). AFM investigations were performed in air and in liquid.

The tapping-mode AFM analysis in air was the same for all the produced targets: ten $(5 \times 5) \mu \mathrm{m}^{2}$ and one $(25 \times 25) \mu \mathrm{m}^{2}$ images were recorded for each target. From each of the ten $(5 \times 5) \mu \mathrm{m}^{2}$ images two root mean square $(R M S)$ values were evaluated using a $(1.5 \times 1.5) \mu \mathrm{m}^{2}$ mask in two different positions inside the image. From each of the $(25 \times 25) \mu \mathrm{m}^{2}$ images, twenty $R M S$ values were evaluated using $(1.5 \times 1.5) \mu \mathrm{m}^{2}$ masks in twenty different positions of the image. In the case of samples presenting surfaces with cracks, the masks were used only in the crack-free areas, as the cracks do not belong to the surface and hence do not define the real roughness of the deposited layers. The final surface roughness value of each of the image sizes was evaluated for each target as the arithmetic mean of all the RMS values measured for that specific image size (i.e., $\overline{R M S}$ ).

\subsubsection{Results}

2.5.2.1. Layer-growth studies from DMF solution. The growth mechanism of the layers was studied as a function of plating time by measuring the $\overline{R M S}$ of air-dried targets. Twelve targets were produced using different deposition times: the first target was produced after 15 min plating and the subsequent ones after increments of $15 \mathrm{~min}$ up to $180 \mathrm{~min}$. The targets were prepared using a $0.22 \mathrm{mM}$ Nd salt (i.e., MC), Ti5 deposition substrates, at a current density of $0.7 \mathrm{~mA} / \mathrm{cm}^{2}$, and DMF as plating solvent. The growth study was restricted to DMF because it showed very promising results, as we briefly reported in [17] where some preliminary tests with this solvent were described.

In Fig. 3 the $\overline{R M S}$ trends of the growing layer show an almost constant behaviour (average value ca. $14 \mathrm{~nm}$ ) during the whole period of deposition $(3 \mathrm{~h}$ ): the surface roughness does not undergo major variations. This is in contrast to similar studies performed 

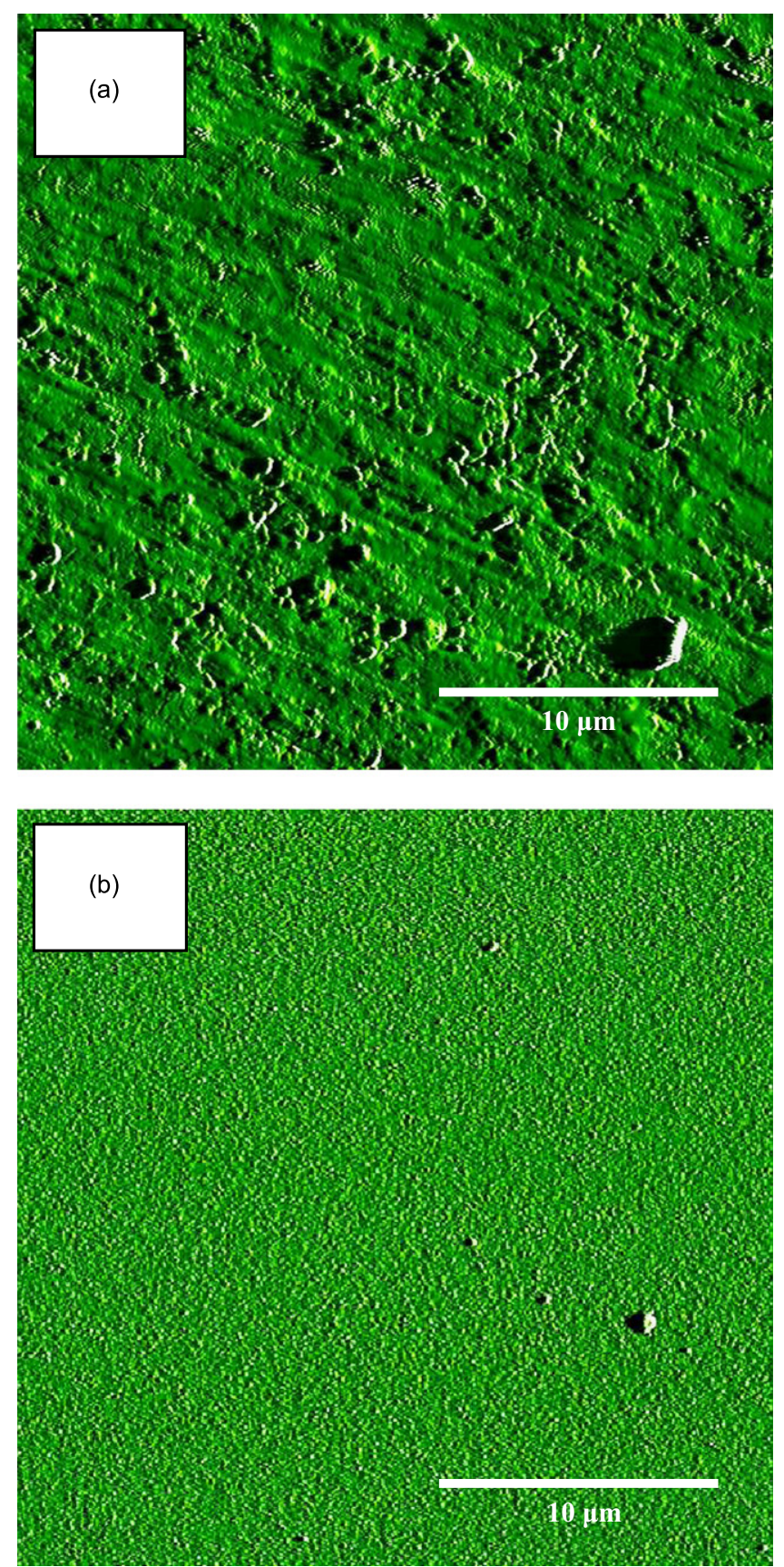

Fig. 2. $(25 \times 25) \mu \mathrm{m}^{2}$ amplitude AFM images of the Ti3 (a) and Ti5 (b) deposition substrates.

in IP + IB on rougher substrates, where the roughness during layer growth increased by a factor of $2-5$. Moreover, all the AFM images recorded for this layer-growth study showed no surface cracking. See for example the $(5 \times 5) \mu \mathrm{m}^{2}$ image of the deposit grown for 180 min shown in Fig. 4. The analysis of such images and the evaluated constant $\overline{R M S}$ trends suggest that the layer growing on the Ti5 cathode during a MC plating experiment performed in DMF follows a Frank-van der Merwe mechanism (layer-by-layer growth mechanism).

2.5.2.2. Influence of the plating solvent and of the drying environment. AFM studies in air were performed on targets produced from MC solution, after drying for one month either in air or in a glove-box where an $\mathrm{Ar}$ inert environment was maintained.
The solvents used for the platings were IP $+\mathrm{IB}$, pyridine, and DMF; the deposition substrates were Ti3 foils. The $\overline{R M S}$ values of the analysis are reported in Table 3.

Table 3 clearly demonstrates that, independently of the chosen drying environment, the roughest samples are those obtained using pyridine, whereas those produced in DMF are the smoothest. No differences in $\overline{R M S}$ values within experimental uncertainties were found for each kind of sample dried in air or in Ar. The analysis of the recorded AFM images showed that samples characterized by cracking of the layers present surface troughs regardless of whether they were dried in air or Ar.

Fig. 5 shows a $(25 \times 25) \mu \mathrm{m}^{2}$ image of the DMF sample after drying in the inert environment.

Unlike the pyridine and IP+IB layers, characterized by severe surface cracking (see, e.g., Fig. 3a in [19] for targets made from IP + IB on Ti3 substrates), the DMF sample shows almost no cracks, except for those mostly arising from the surface defects (i.e., white outgrowths in Fig. 5).

2.5.2.3. Influence of the electrolyte concentration. Air-dried HC, MC, and LC targets produced using Ti5 as deposition substrates and DMF as plating solvent were investigated in air. The results of the analysis reported in Table 3 show that the $\mathrm{HC}$ target is much rougher than the MC and LC targets, which have identical roughness. Moreover, Table 3 shows that DMF MC targets prepared on Ti5 substrates are smoother than the same targets prepared on $\mathrm{Ti} 3$ foils.

We notice that the recorded AFM images revealed no cracks in the surfaces of the HC, MC, and LC targets plated from DMF.

2.5.2.4. Influence of the current density. AFM analyses in air were performed on air-dried MC targets produced using different constant current densities, namely $0.17,0.3$, and $1.3 \mathrm{~mA} / \mathrm{cm}^{2}$. Ti5 was used as deposition substrate, and DMF as plating solvent. The $\overline{R M S}$ values of the analysis are reported in Table 3 , whereas the corresponding $(25 \times 25) \mu \mathrm{m}^{2}$ images of the deposits are shown in Fig. 6.

Table 3 shows that only the intermediate current density of $0.3 \mathrm{~mA} / \mathrm{cm}^{2}$ gives $\overline{R M S}$ values similar to those recorded for the $0.7 \mathrm{~mA} / \mathrm{cm}^{2}$ experiments. Both higher (i.e., $1.3 \mathrm{~mA} / \mathrm{cm}^{2}$ ) and lower (i.e., $0.17 \mathrm{~mA} / \mathrm{cm}^{2}$ ) constant current densities result in much rougher final deposits. In particular, the roughest deposit is obtained with $0.17 \mathrm{~mA} / \mathrm{cm}^{2}$. These results are well evidenced by the $(25 \times 25) \mu \mathrm{m}^{2}$ images of the 0.17 and $1.3 \mathrm{~mA} / \mathrm{cm}^{2}$ samples shown in Fig. 6, where both surfaces present evident outgrowths (i.e., white spots in the figures), which are bigger in the case of the targets made at $1.3 \mathrm{~mA} / \mathrm{cm}^{2}$, but not covering the entire analyzed area (c), and smaller but spread over the entire surface in the case of the targets made at $0.17 \mathrm{~mA} / \mathrm{cm}^{2}$ (a). No surface cracks were noted for any of the investigated samples prepared with DMF.

2.5.2.5. Liquid AFM study from IP+IB solution. Fig. 7 shows the results of a liquid AFM study (already briefly reported in [17]), which was performed on a MC target produced using Ti3 as deposition substrate, and IP + IB as plating solvent. At the end of the deposition, the cell was top-sealed, the anode was removed, and the solvent was extracted till only the cathode surface was covered by liquid. Then, the PEEK body of the cell was removed, leaving the cathode deposit covered in liquid: an AFM analysis in contact mode was performed recording one $(25 \times 25) \mu \mathrm{m}^{2}$ image (Fig. 7a). After the liquid was removed from the cathode assembly and the target dried, a tapping-mode AFM analysis was performed and $\mathrm{a}(25 \times 25) \mu \mathrm{m}^{2}$ image was recorded (Fig. 7b). Both images were elaborated using the WSxM 5.0 version developed by Nanotech Electronica [18]. 
Table 3

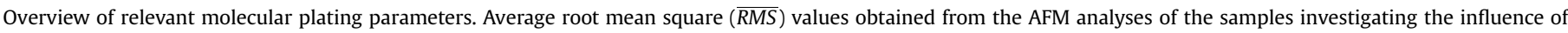
plating solvent, drying environment, electrolyte concentration, and current density on the surface roughness of the produced layers.

\begin{tabular}{|c|c|c|c|c|c|c|}
\hline Substrate type & Solvent & Drying environment & Concentration & Current density $\left(\mathrm{mA} / \mathrm{cm}^{2}\right)$ & Scan size $\left(\mu \mathrm{m}^{2}\right)$ & $\overline{R M S}(\mathbf{n m})$ \\
\hline Ti3 & Pyridine & Air & MC & 0.7 & $\begin{array}{l}(5 \times 5) \\
(25 \times 25)\end{array}$ & $\begin{array}{l}242 \pm 140 \\
372 \pm 190\end{array}$ \\
\hline $\mathrm{Ti} 3$ & Pyridine & $\mathrm{Ar}$ & MC & 0.7 & $\begin{array}{l}(5 \times 5) \\
(25 \times 25)\end{array}$ & $\begin{array}{l}320 \pm 160 \\
350 \pm 180\end{array}$ \\
\hline $\mathrm{Ti} 3$ & $\mathrm{IP}+\mathrm{IB}$ & Air & MC & 0.7 & $\begin{array}{l}(5 \times 5) \\
(25 \times 25)\end{array}$ & $\begin{array}{l}150 \pm 40 \\
190 \pm 70\end{array}$ \\
\hline Ti3 & $\mathrm{IP}+\mathrm{IB}$ & $\mathrm{Ar}$ & $\mathrm{MC}$ & 0.7 & $\begin{array}{l}(5 \times 5) \\
(25 \times 25)\end{array}$ & $\begin{array}{l}140 \pm 60 \\
180 \pm 80\end{array}$ \\
\hline $\mathrm{Ti} 3$ & DMF & Air & MC & 0.7 & $\begin{array}{l}(5 \times 5) \\
(25 \times 25)\end{array}$ & $\begin{array}{r}61 \pm 24 \\
130 \pm 40\end{array}$ \\
\hline $\mathrm{Ti} 3$ & $\mathrm{DMF}$ & $\mathrm{Ar}$ & MC & 0.7 & $\begin{array}{l}(5 \times 5) \\
(25 \times 25)\end{array}$ & $\begin{array}{r}52 \pm 23 \\
110_{ \pm} 50\end{array}$ \\
\hline Ti5 & DMF & Air & $\mathrm{HC}$ & 0.7 & $\begin{array}{l}(5 \times 5) \\
(25 \times 25)\end{array}$ & $\begin{array}{l}70 \pm 21 \\
79 \pm 14\end{array}$ \\
\hline Ti5 & DMF & Air & MC & 0.7 & $\begin{array}{l}(5 \times 5) \\
(25 \times 25)\end{array}$ & $\begin{array}{l}17 \pm 8 \\
18 \pm 9\end{array}$ \\
\hline Ti5 & DMF & Air & LC & 0.7 & $\begin{array}{l}(5 \times 5) \\
(25 \times 25)\end{array}$ & $\begin{array}{l}17 \pm 3 \\
18 \pm 8\end{array}$ \\
\hline Ti5 & DMF & Air & MC & 0.17 & $\begin{array}{l}(5 \times 5) \\
(25 \times 25)\end{array}$ & $\begin{array}{r}110_{ \pm} 35 \\
130 \pm 25\end{array}$ \\
\hline Ti5 & DMF & Air & MC & 0.3 & $\begin{array}{l}(5 \times 5) \\
(25 \times 25)\end{array}$ & $\begin{array}{l}10 \pm 4 \\
12 \pm 5\end{array}$ \\
\hline Ti5 & $\mathrm{DMF}$ & Air & MC & 1.3 & $\begin{array}{l}(5 \times 5) \\
(25 \times 25)\end{array}$ & $\begin{array}{l}70 \pm 30 \\
80 \pm 22\end{array}$ \\
\hline
\end{tabular}

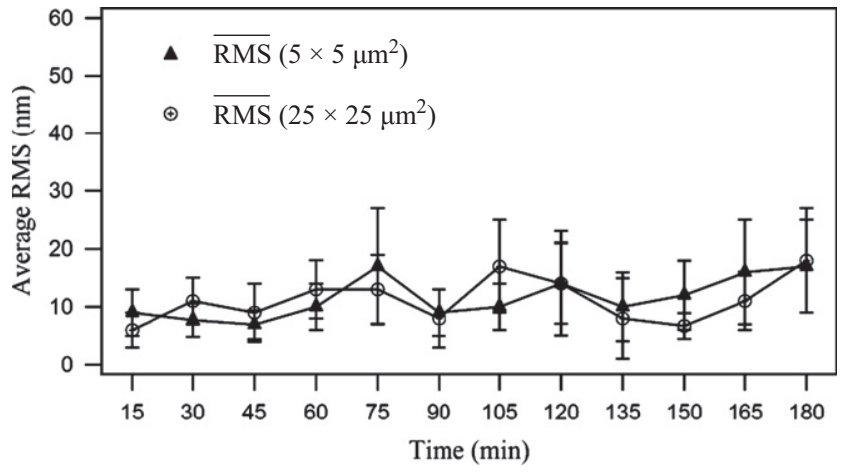

Fig. 3. $\overline{R M S}$ vs. time trend of the layer-growth study of the air-dried targets produced using $0.22 \mathrm{mM}$ Nd salt with DMF and Ti5 deposition substrates.

The 3D AFM images of Fig. 7 indicate that the cracking of the surfaces develops after the removal of the liquid and the drying of the deposited layer.

\subsection{Scanning electron microscopy (SEM) studies}

\subsubsection{Experiments}

The morphology of the targets was studied using scanning electron microscopy (SEM) (Philips XL30). The microscope was operated at $20 \mathrm{kV}$. The pressure inside the vacuum chamber was $5 \mathrm{mPa}$. Backscattered and secondary electrons were detected. A magnification factor of $1000 \times$ was used.

\subsubsection{Results}

Fig. 8 shows $1000 \times$ SEM images of three MC samples produced using the following deposition substrates and plating solvents: (a) Ti3 and pyridine, (b) Ti3 and DMF, (c) Ti5 and DMF. All samples were airdried. Among the several SEM images recorded, these particular ones

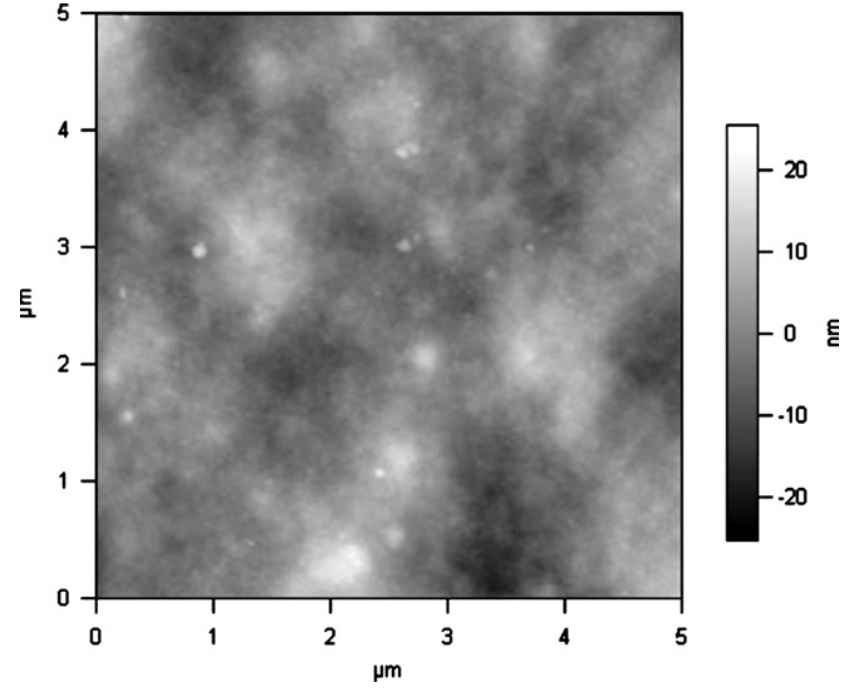

Fig. 4. Layer-growth studies from DMF solution. $(5 \times 5) \mu \mathrm{m}^{2}$ topography AFM image of the sample plated for 180 min using Ti5 substrate and MC plating solution in DMF.

were chosen for display here because of the important surface morphology information they convey.

Fig. 8a shows a large-area image of an air-dried pyridine MC target. The surface of the sample suffers from severe cracking and it is visibly rough.

Figs. $8 \mathrm{~b}$ and $\mathrm{c}$ show an important effect of the deposition substrate (Ti3 vs. Ti5) on the surface morphology of the deposits. These images indicate that MC targets prepared using DMF and a Ti3 substrate (Fig. 8b) exhibit cracks in the layer, caused mainly by the grown surface defects, as already shown in Fig. 5. If, instead, a smoother deposition substrate is used, i.e., Ti5, MC targets produced using DMF (Fig. 8c) show no surface cracks (see also Fig. 4). In contrast, $\mathrm{MC}$ experiments using IP+IB (see Fig. 2b in [14]) 


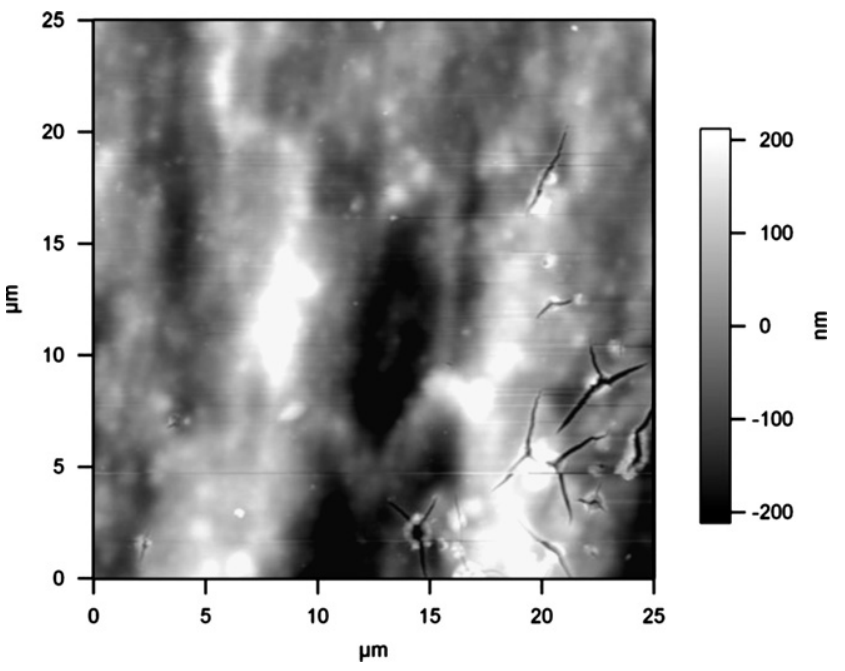

Fig. 5. Influence of the plating solvent and of the drying environment. $(25 \times 25) \mu \mathrm{m}^{2}$ topography AFM image of the sample produced using MC plating solution, Ti3 substrate, DMF, and dried in an Ar inert environment.

or pyridine showed the presence of cracks in the deposited layers also when Ti5 substrates were used.

\subsection{Radiographic imaging (RI) studies}

\subsubsection{Experiments}

Radioactive targets were produced by performing MPs of Nd solutions containing a radioactive tracer of the element to be plated ( $\mathrm{Nd}$ : ${ }^{147} \mathrm{Nd}, \beta^{-}, t_{1 / 2}=10.98 \mathrm{~d}, E_{\gamma}=91 \mathrm{keV}$ ). The tracer was produced in a neutron capture reaction $(n, \gamma)$ on ${ }^{146} \mathrm{Nd}$ present in the used $\mathrm{Nd}$ of natural isotopic composition $\left({ }^{\text {nat }} \mathrm{Nd}\right)$ by irradiating an aliquot of $100 \mu \mathrm{L}$ of the stock solution with thermal neutrons in the TRIGA Mainz research reactor. The homogeneity of such targets was inspected by using radiographic imaging (RI), employing a FUJIFILM FLA 7000 equipped with reusable imaging plates and a $650 \mathrm{~nm}$ laser for the reading process. To verify the homogeneity of the target, the image was overlaid by a grid of square spots with an area of $0.25 \mathrm{~mm}^{2}$ each. The spatial resolution for $\gamma$-emitting nuclides was $<200 \mu \mathrm{m}$ [19].

\subsubsection{Results}

Fig. 9a shows the 3D graph of a sample obtained using IP + IB as plating solvent and $\mathrm{Ti} 3$ as deposition substrate. Fig. 9b displays the graph of a sample obtained using DMF and Ti5.

The images show a definite improvement in surface homogeneity of the deposited layers once DMF is chosen as plating solvent and Ti5 as deposition substrate. Experiments showed that better homogeneity of the surfaces is achieved also when DMF is used instead of pyridine in the preparation of MC targets on Ti3 foils.

\subsection{X-ray photoelectron spectroscopy (XPS) studies}

\subsubsection{Experiments}

X-ray photoelectron spectroscopy (XPS) was used to perform the chemical surface characterization of the samples by applying $\mathrm{Al} K_{\alpha}$ and $\mathrm{Mg} K_{\alpha}$ radiations. The X-ray source was operated at $10 \mathrm{kV}$ anode voltage and a current of $10 \mathrm{~mA}$. The pass-energy of the hemispherical energy analyzer was $50 \mathrm{eV}$. The pressure inside the ultra-high vacuum chamber was in the range of $(1.2-2.0) \times 10^{-7} \mathrm{~Pa}$. The analyzed samples were six MC targets produced using IP $+\mathrm{IB}$, pyridine, and DMF as plating solvents, and Ti3 foils as deposition
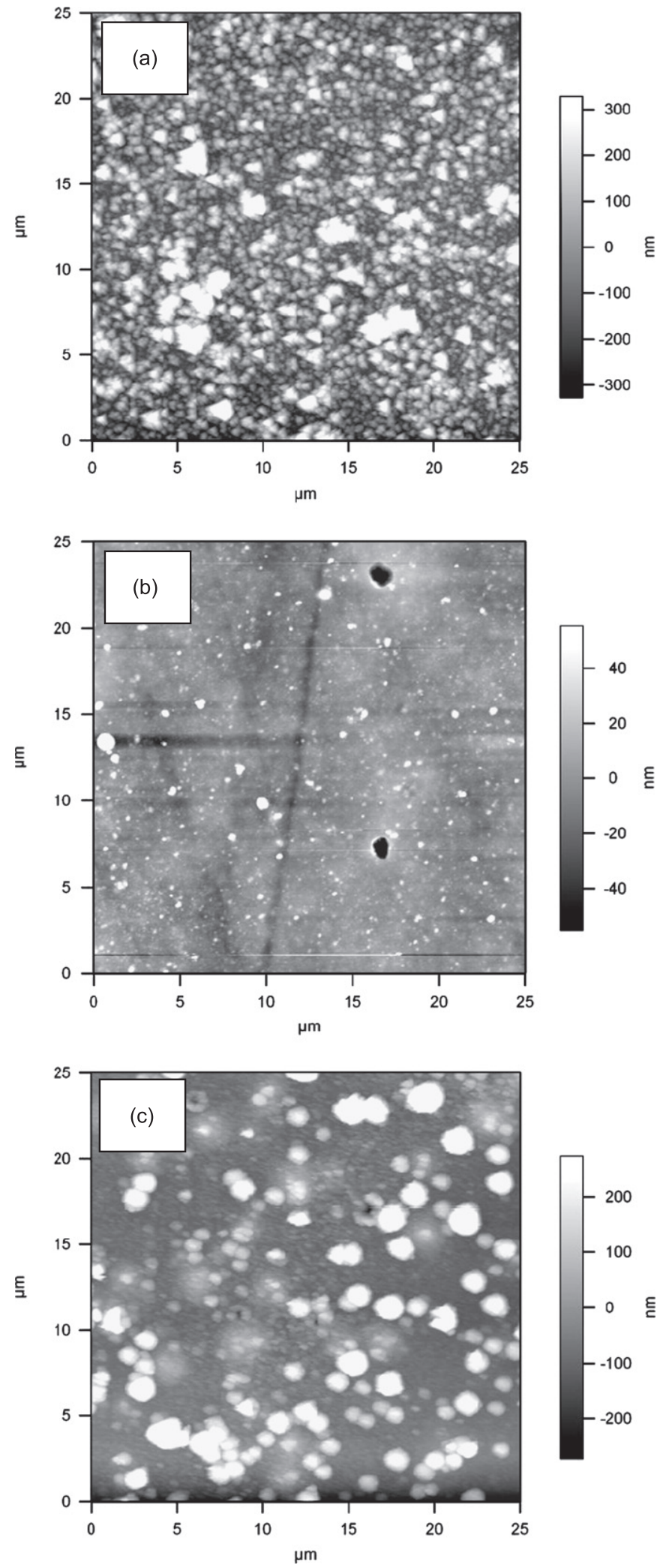

Fig. 6. Influence of the current density. $(25 \times 25) \mu \mathrm{m}^{2}$ topography AFM images of samples produced using MC plating solution in DMF and a Ti5 substrate; deposits obtained after galvanostatic electrolysis at current densities of $0.17 \mathrm{~mA} / \mathrm{cm}^{2}$ (a), $0.3 \mathrm{~mA} / \mathrm{cm}^{2}$ (b), or $1.3 \mathrm{~mA} / \mathrm{cm}^{2}$ (c).

substrates. Two targets were produced in each solvent; one was dried in air, while the other was dried inside a glove-box, where an inert environment was assured by a constant Ar pressure 

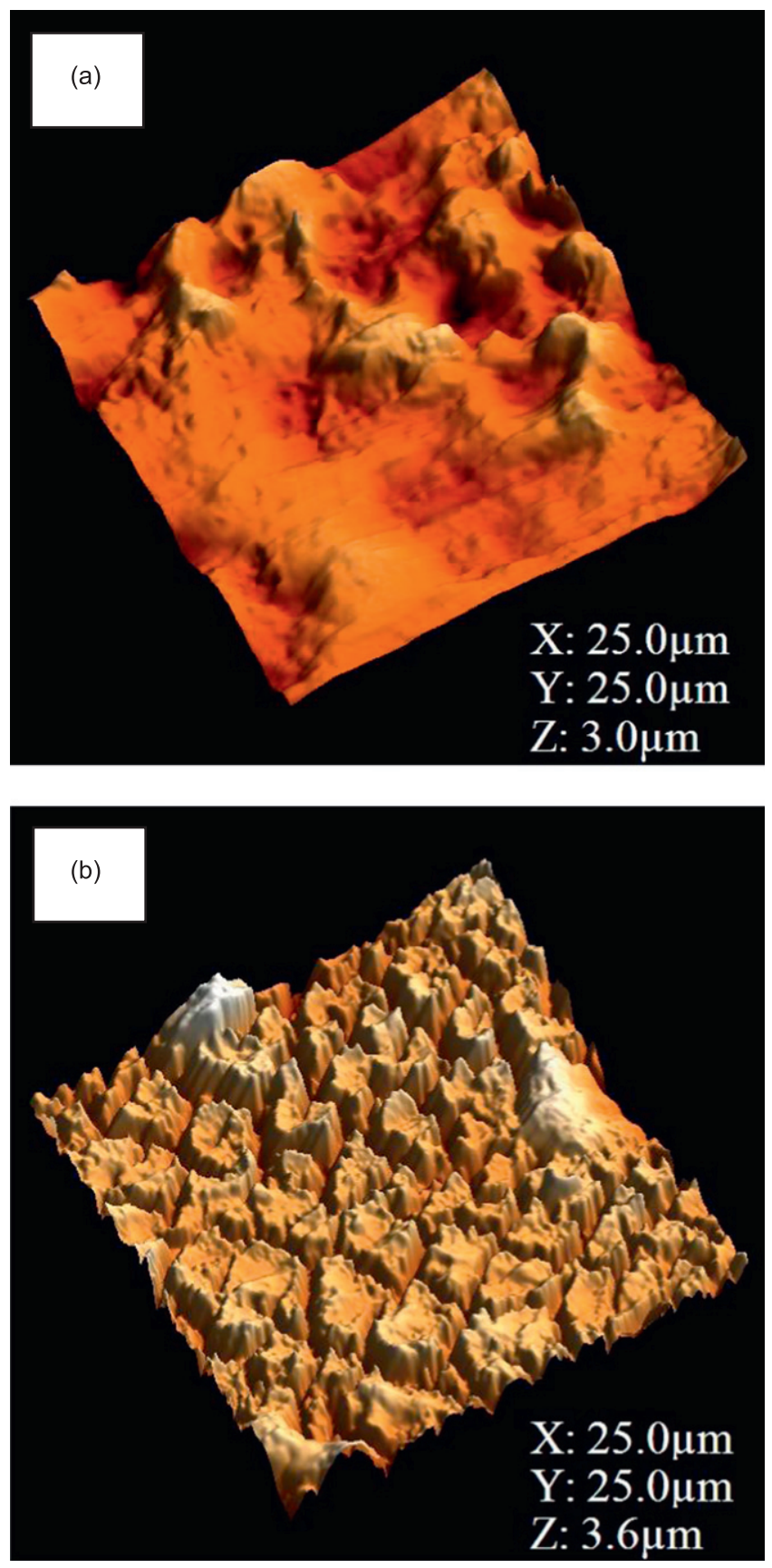

Fig. 7. Liquid AFM study from IP+IB solution. 3D $(25 \times 25) \mu \mathrm{m}^{2}$ topography AFM images of the target produced using Ti3 and MC plating solution in IP+ IB before (a) and after solvent removal and drying (b).

(50 Pa below atmospheric pressure, $\mathrm{O}_{2}<1 \mathrm{ppm}, \mathrm{H}_{2} \mathrm{O}<1 \mathrm{ppm}$ ). We refer to [14] for details about the drying procedure in an inert environment and the subsequent XPS analysis. Drying in different environments was investigated to probe whether reactive or inert environments like, respectively, air or Ar cause different surface chemical reactions to take place, the products of which might be identified by XPS.

After the first surface investigation, the samples underwent 10 min sputtering using $4 \mathrm{kV} \mathrm{Ar}{ }^{+}$ions, followed by further XPS analysis.

The binding energies of the XPS lines of interest were determined by fitting the recorded XPS spectra. The analyses were performed using the CasaXPS software (version 2.3.15), with which the background was subtracted adopting the Shirley
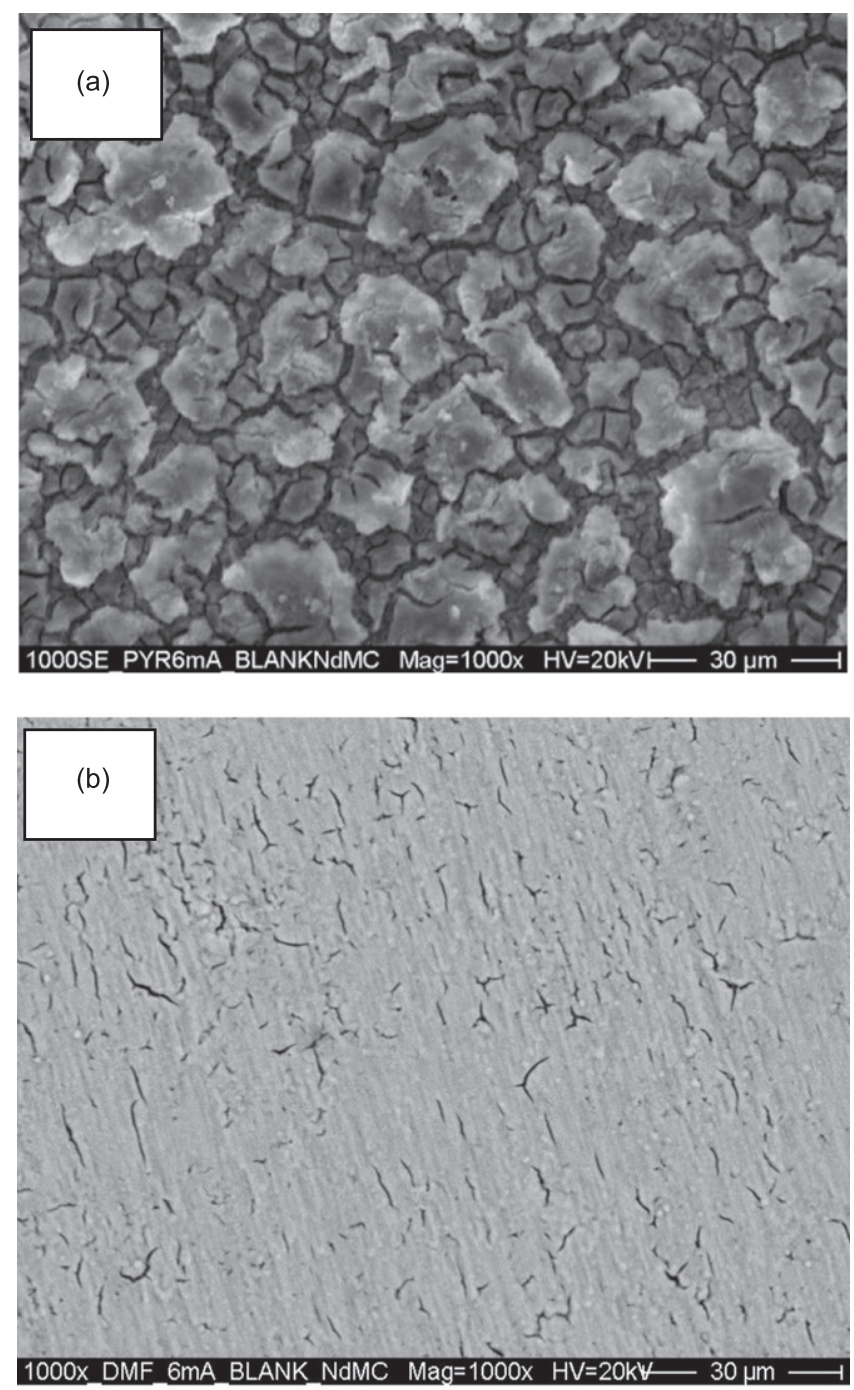

(c)

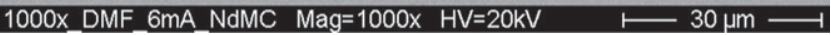

Fig. 8. Influence of substrate surface roughness and plating solvent. 1000× SEM images of the air-dried samples produced using MC plating solution and the following substrate/solvent systems: (a) Ti3/pyridine, (b) Ti3/DMF, (c) Ti5/DMF.

algorithm, and the peaks were fitted using the Gaussian/Lorentzian product formula. As the aim of the present work was mainly to investigate the surface chemistry of the samples after drying in different environments, a detailed chemical surface analysis of the 
(a)

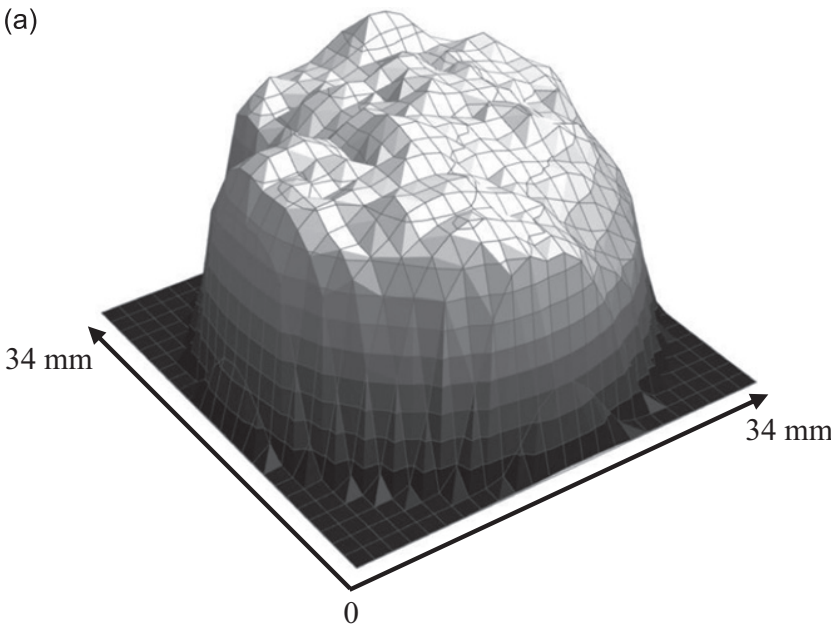

(b)

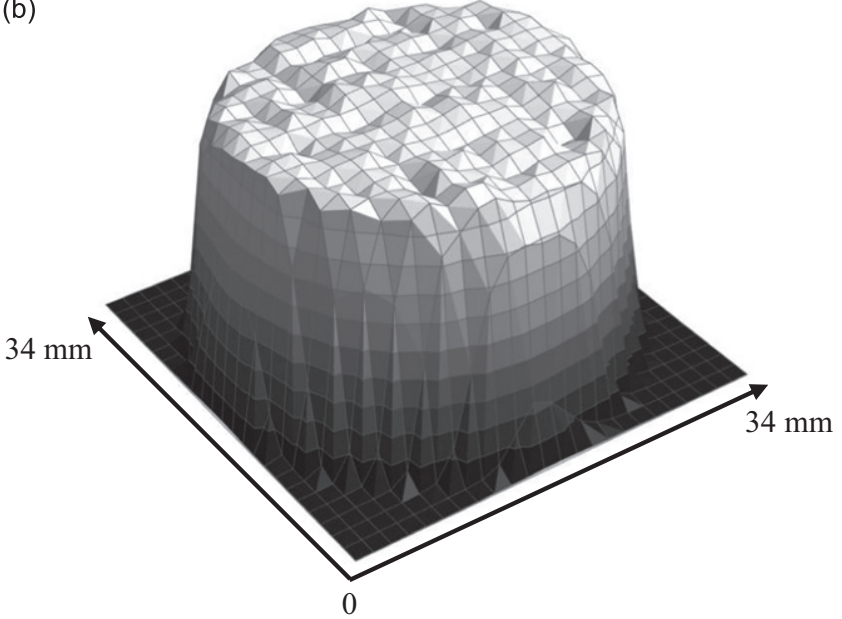

Fig. 9. Influence of substrate surface roughness and plating solvent. RI 3D graphs of samples produced using MC plating solution and the following substrate/solvent systems: (a) Ti3/IP + IB, (b) Ti5/DMF.

deposits was performed only for C, which was known from [14] to be the main element composing the outer layer of the produced samples. The $C 1 \mathrm{~s}$ spectra are therefore the only ones to be shown with multicomponent fitting analysis, which was always modelled by fixing the separations in binding energy, the intensity ratios, and the full widths at half maxima (FWHM) of the different $\mathrm{C} 1 \mathrm{~s}$ components of IP $+\mathrm{IB}, \mathrm{DMF}$, and pyridine. For the IP $+\mathrm{IB}$ and DMF samples dried both in air and in Ar environment, the analysis before sputtering required correcting the binding energies for the surface charging using one of the components of the $C 1 \mathrm{~s}$ lines: the $284.9 \mathrm{eV}$ component [20] for IP $+\mathrm{IB}$, and the $285.8 \mathrm{eV}$ component [21] for DMF. After sputtering, the imprecise fittings of the reference $C 1 \mathrm{~s}$ peaks required the use of a higher binding energy peak (ca. $289 \mathrm{eV}$ ) present in the same $\mathrm{C} 1 \mathrm{~s}$ spectra to correct for the surface charge effect. For the air- and Ar-dried pyridine samples, instead, the correction of the binding energies was performed both before and after sputtering using the intense $\mathrm{N}$ 1s line of pyridine at $400.2 \mathrm{eV}$ [22]. The experimental uncertainty of the binding energies is $\pm 0.1 \mathrm{eV}$.

\subsubsection{Results}

The XPS analyses of the six MC targets never showed the presence of Ti signals, indicating that all the deposited layers are thick.

The $\mathrm{Nd}$ analysis of the samples required the use of $\mathrm{Mg} K_{\alpha}$ radiation to avoid an interference with the Auger lines of oxygen in the binding energy region of $\mathrm{Nd} 3 \mathrm{~d}$. The $\mathrm{Nd} 3 \mathrm{~d}$ spectra of all the samples dried in Ar environment (not shown) were identical to those of the air-dried targets, except for smaller intensities of the recorded peaks.

Differences among the recorded XPS signals of the IP $+\mathrm{IB}, \mathrm{DMF}$ and pyridine spectra were noted only for the $C 1 \mathrm{~s}$ lines of the airand Ar-dried samples.

2.8.2.1. Samples prepared from IP+IB. The XPS analyses of the airand Ar-dried IP + IB samples showed the presence of the following elements: C, O, Pd, and $\mathrm{Nd}$. The corresponding XPS signals were: C 1s, O 1s, Pd 3d, Nd 3d, and Nd 4d. Fig. 10 shows the spectra of Nd $3 \mathrm{~d}(\mathrm{a})$ and $C 1 \mathrm{~s}$ (b) of the sample dried in air and Fig. 10c the $C 1 \mathrm{~s}$ spectra of the sample dried in Ar environment. The model applied for the multicomponent fitting analysis of the $C 1 \mathrm{~s}$ peaks took into account only the C $1 \mathrm{~s}$ components of isobutanol, as isopropanol corresponds to just 3\% of the total volume of the solvent. According to literature [20], the C 1s components of isobutanol have binding energies at $284.9 \mathrm{eV}, 285.0 \mathrm{eV}$, and $286.5 \mathrm{eV}$, with an intensity ratio of $2: 1: 1$. Table 4 shows the ratios of the total peak areas $\mathrm{C} 1 \mathrm{~s} / \mathrm{Nd} 3 \mathrm{~d}, \mathrm{O} 1 \mathrm{~s} / \mathrm{C} 1 \mathrm{~s}$, and the ratios between the sum of the peaks fitting a certain spectral component and a total peak area, like the ratios reported as C 1s (ca. $285 \mathrm{eV}$ )/Nd 3d, C 1s (ca. $286 \mathrm{eV}$ )/Nd 3d, and C 1s (ca. $289 \mathrm{eV}$ )/Nd 3d. The ratios were evaluated before and after $10 \mathrm{~min}$ sputtering.

The measured binding energy of the $\mathrm{Nd} 3 \mathrm{~d}_{5 / 2}$ peak is $982.8 \mathrm{eV}$ (Fig. 10a) and can be compared to the literature value of $983.1 \mathrm{eV}$ [23] for $\mathrm{Nd}^{3+}$. This indicates that $\mathrm{Nd}$ is present as $\mathrm{Nd}^{3+}$ in the deposited layer (possibly as carboxylate, oxide, or hydroxide) [14].

The $C$ 1s spectra reported in Figs. 10b and c show the presence of two components: the $\mathrm{C} 1 \mathrm{~s}$ peaks at ca. $285.0 \mathrm{eV}$, which remarkably decrease upon $\mathrm{Ar}^{+}$sputtering, are due to physisorbed aliphatic carbon of the mixed isopropanol/isobutanol solvent. The peaks at the higher binding energy (i.e., 289.9 and $289.6 \mathrm{eV}$ for airand Ar-dried samples, respectively) can be attributed, according to literature, to COOM - metal carboxylate - (289.0 eV [23]) groups formed during the plating process, which are chemisorbed, as follows from the observation that they are not easily removed by the sputtering. This shows that the solvent undergoes electrolysis during the MP process and becomes oxidized.

For a more detailed analysis of the $\mathrm{Nd} 3 \mathrm{~d}$ and $\mathrm{C} 1 \mathrm{~s}$ spectra of the IP+IB samples we refer to [14].

The spectra of Fig. 10, as well as the $\mathrm{C} 1 \mathrm{~s} / \mathrm{Nd} 3 \mathrm{~d}$ ratios reported in Table 4, show that for both air- and Ar-dried samples the intensity of the $\mathrm{Nd} 3 \mathrm{~d}$ signal increases, while that of $\mathrm{C} 1 \mathrm{~s}$ decreases when the surface is sputtered with $\mathrm{Ar}^{+}$for $10 \mathrm{~min}$. This result shows that the Nd deposit is covered with a layer of solvent.

A consequence of drying the samples in air can be inferred from the different intensity ratios of the two $C 1$ s components at 0 min sputtering in Figs. 10b and c: the 1:1 ratio of the Ar-dried sample becomes almost 1:2 after drying in air. From the analysis of the C 1s (ca. $285 \mathrm{eV}$ )/Nd 3d and C 1s (ca. $289 \mathrm{eV}$ )/Nd 3d ratios it is evident that while the intensity of the chemisorbed $\mathrm{C} 1 \mathrm{~s}$ (ca. $289 \mathrm{eV}$ ) component is not affected by the method of drying, the physisorbed one (ca. $285.0 \mathrm{eV}$ ) decreases when the sample is dried in air. As a consequence more intense $\mathrm{Nd} 3 \mathrm{~d}$ signals, hence smaller $\mathrm{C} / \mathrm{Nd}$ ratios (see Table 4), are recorded for the air-dried sample.

2.8.2.2. Samples prepared from DMF. As regards the XPS analyses of the targets prepared in DMF, the spectra of both air- and Ar-dried samples showed the presence of the following elements: $\mathrm{C}, \mathrm{N}, \mathrm{O}$, and $\mathrm{Nd}$. The corresponding XPS signals were: $\mathrm{C} 1 \mathrm{~s}, \mathrm{~N} \mathrm{1s}, \mathrm{O} 1 \mathrm{~s}, \mathrm{Nd}$ $3 d$, and Nd 4d. No signals of Pd were detected. Fig. 11 shows the spectra of Nd 3d (a) and C 1s (b) of the sample dried in air, and Fig. 11c the $\mathrm{C} 1 \mathrm{~s}$ spectra of the sample dried in $\mathrm{Ar}$ environment. 
(a) $\times 10^{3}$

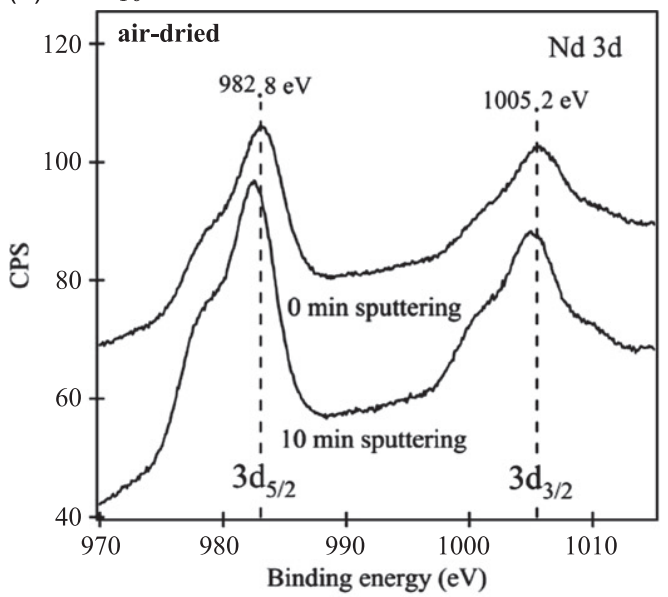

(b) $\times 10^{3}$

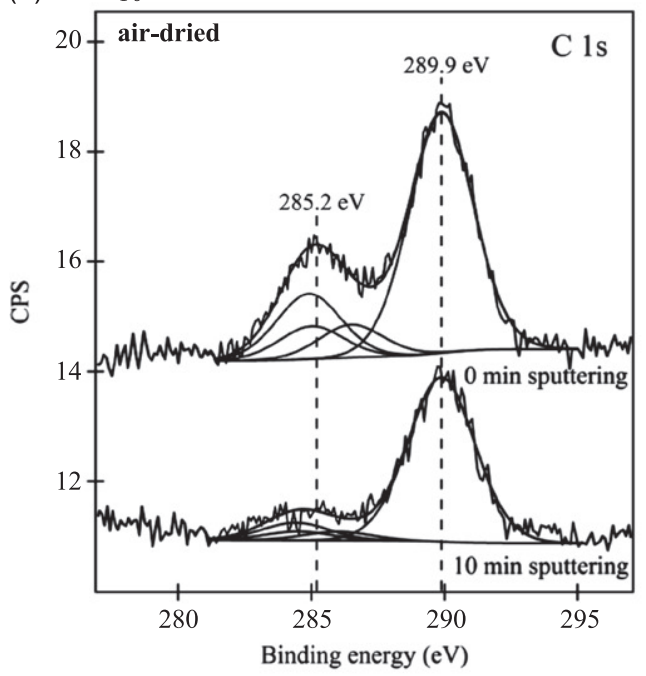

(c) $\times 10^{3}$

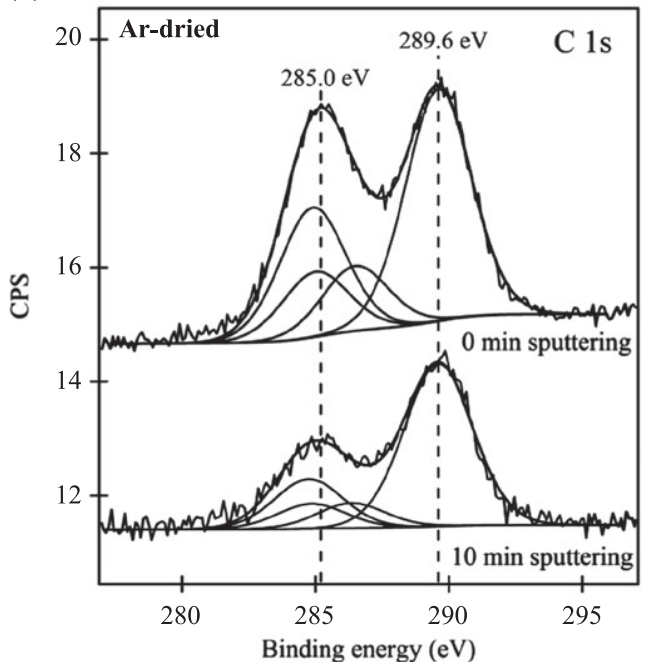

Fig. 10. XPS spectra of samples obtained after plating on Ti3 substrates using MC plating solution in IP+IB: (a) Nd 3d (air-dried), (b) C 1s (air-dried), and (c) C 1s (Ar-dried) before sputtering (indicated as 0 min sputtering in the figure), and after 10 min sputtering with $\mathrm{Ar}^{+}$ions. Offsets were applied for clarity.

According to literature [21], the C 1 s components of DMF have binding energies at $285.8 \mathrm{eV}$, and $288.8 \mathrm{eV}$ with an intensity ratio of $2: 1$.
Table 4

Ratios of the peak areas of some of the detected elements before and after $10 \mathrm{~min}$ sputtering.

\begin{tabular}{|c|c|c|c|c|c|}
\hline \multirow[t]{2}{*}{ Sample } & \multirow{2}{*}{$\begin{array}{l}\text { Ratios of XPS } \\
\text { peak areas }\end{array}$} & \multicolumn{2}{|l|}{ Air } & \multicolumn{2}{|l|}{$\mathrm{Ar}$} \\
\hline & & $\begin{array}{l}\mathbf{0} \text { min } \\
\text { sputtering }\end{array}$ & $\begin{array}{l}10 \mathrm{~min} \\
\text { sputtering }\end{array}$ & $\begin{array}{l}0 \text { min } \\
\text { sputtering }\end{array}$ & $\begin{array}{l}10 \text { min } \\
\text { sputtering }\end{array}$ \\
\hline \multirow[t]{4}{*}{$\mathbf{I P}+\mathbf{I B}$} & C 1s/Nd 3d & 0.04 & 0.015 & 0.11 & 0.020 \\
\hline & 0 1s/C 1s & 6 & 10 & 4 & 9 \\
\hline & $\begin{array}{l}\text { C 1s (ca. } \\
285 \mathrm{eV}) / \mathrm{Nd} 3 \mathrm{~d}\end{array}$ & 0.014 & 0.0026 & 0.05 & 0.008 \\
\hline & $\begin{array}{l}\text { C 1s (ca. } \\
289 \mathrm{eV}) / \mathrm{Nd} 3 \mathrm{~d}\end{array}$ & 0.026 & 0.012 & 0.04 & 0.011 \\
\hline \multirow[t]{4}{*}{ DMF } & C 1s/Nd 3d & 0.05 & 0.011 & 0.10 & 0.014 \\
\hline & 0 1s/C 1s & 6 & 15 & 5 & 12 \\
\hline & $\begin{array}{l}\text { C } 1 \mathrm{~s} \text { (ca. } \\
286 \mathrm{eV}) / \mathrm{Nd} \text { 3d }\end{array}$ & 0.022 & 0.0018 & 0.07 & 0.005 \\
\hline & $\begin{array}{l}\text { C 1s (ca. } \\
289 \mathrm{eV}) / \mathrm{Nd} 3 \mathrm{~d}\end{array}$ & 0.03 & 0.009 & 0.028 & 0.009 \\
\hline \multirow[t]{4}{*}{ Pyridine } & C 1s/Nd 3d & 0.9 & 0.14 & 1.1 & 0.20 \\
\hline & 0 1s/C 1s & 1.3 & 1.4 & 1.2 & 1.4 \\
\hline & $\begin{array}{l}\text { C 1s (ca. } \\
286 \mathrm{eV}) / \mathrm{Nd} 3 \mathrm{~d}\end{array}$ & 0.8 & 0.13 & 1.0 & 0.17 \\
\hline & $\begin{array}{l}\text { C 1s (ca. } \\
289 \mathrm{eV}) / \mathrm{Nd} 3 \mathrm{~d}\end{array}$ & 0.10 & 0.015 & 0.12 & 0.021 \\
\hline
\end{tabular}

The XPS spectra of the DMF samples (Fig. 11) are quite similar to those of the IP+IB samples (Fig. 10). The measured binding energy of the $\mathrm{Nd} 3 \mathrm{~d}_{5 / 2}$ peak (i.e., $983.6 \mathrm{eV}$, Fig. 11a) confirms that $\mathrm{Nd}$ is deposited as $\mathrm{Nd}^{3+}$ also in DMF (possibly as carboxylate, oxide, or hydroxide). The $C$ 1s spectra reported in Figs. 11b and $c$ show again the presence of two components: the components of the physisorbed solvent at ca. $286 \mathrm{eV}$ and $289 \mathrm{eV}$, and the components of chemisorbed species at $290.2 \mathrm{eV}$ in air, and at $289.4 \mathrm{eV}$ in $\mathrm{Ar}$ environment. As in the case of IP $+\mathrm{IB}$, the $\mathrm{C} 1 \mathrm{~s}$ peak of the chemisorbed species can be attributed to possible COOM metal carboxylate - groups formed during the plating process. The produced samples are again characterized by an outer layer of solvent which covers the Nd deposit, as indicated by the spectra of Fig. 11, as well as by the ratios $\mathrm{C} 1 \mathrm{~s} / \mathrm{Nd} 3 \mathrm{~d}$ reported in Table 4 . These ratios show that, for both air- and Ar-dried samples, the intensity of the $\mathrm{Nd} 3 \mathrm{~d}$ signal increases with sputtering time, while that of $\mathrm{C} 1 \mathrm{~s}$ decreases.

As in the case of MPs in IP+IB, the difference between drying in air or $\mathrm{Ar}$ is reflected by the smaller $\mathrm{C} 1 \mathrm{~s} / \mathrm{Nd} 3 \mathrm{~d}$ ratio in air than in $\mathrm{Ar}$, i.e., 0.05 instead of 0.10 (Table 4). This difference is also confirmed by the larger value of the $\mathrm{C} 1 \mathrm{~s}$ (ca. $286 \mathrm{eV}$ )/Nd $3 \mathrm{~d}$ ratio in $\mathrm{Ar}$ than in air. Therefore, also in the case of DMF, the 1:1 ratio of the $C 1 \mathrm{~s}$ signals of the Ar-dried sample becomes almost $1: 2$ after drying in air. The C 1s (ca. $289 \mathrm{eV}) / \mathrm{Nd} 3 \mathrm{~d}$ ratios are very similar both in air and in Ar, indicating that the chemisorbed products are not considerably affected by drying in different environments.

2.8.2.3. Samples prepared from pyridine. The XPS analyses of the air- and Ar-dried pyridine samples showed the presence of the following elements: C, N, O, Pd, and Nd. The corresponding XPS signals were: C 1s, N 1s, O 1s, Pd 3d, Nd 3d, and Nd 4d. Fig. 12 shows the spectra of $\mathrm{Nd} 3 \mathrm{~d}$ (a) and $\mathrm{C} 1 \mathrm{~s} \mathrm{(b)}$ of the sample dried in air, and Fig. $12 \mathrm{c}$ the $\mathrm{C} 1 \mathrm{~s}$ spectra of the sample dried in $\mathrm{Ar}$ environment. According to literature [22], the $C 1$ s components of pyridine have binding energies at $285.5 \mathrm{eV}, 285.9 \mathrm{eV}$, and $286.3 \mathrm{eV}$, with an intensity ratio of $2: 1: 2$.

The spectra of Fig. 12a show that the Nd 3d signal before sputtering is quite low. It is much lower than the Nd 3d signals of the corresponding (unsputtered) IP $+\mathrm{IB}$ and DMF samples 


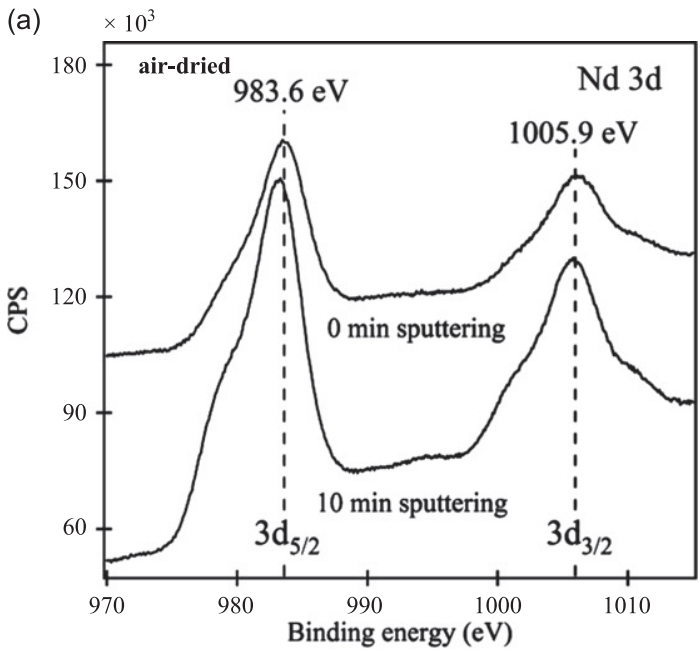

(b)

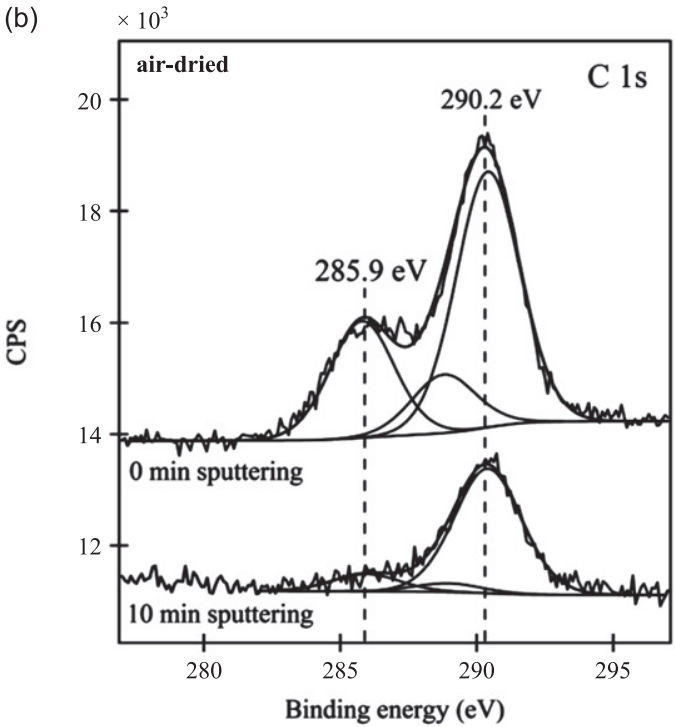

(c)

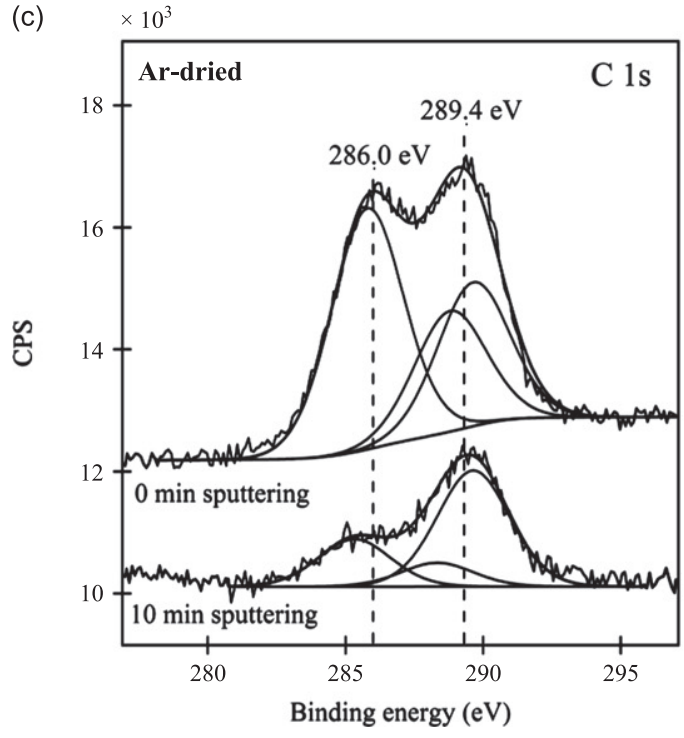

Fig. 11. XPS spectra of samples obtained after plating on Ti3 substrates using MC plating solution in DMF: (a) Nd 3d (air-dried), (b) C 1s (air-dried), and (c) C 1s (Ar-dried) before sputtering (indicated as 0 min sputtering in the figure), and after 10 min sputtering with $\mathrm{Ar}^{+}$ions. Offsets were applied for clarity.
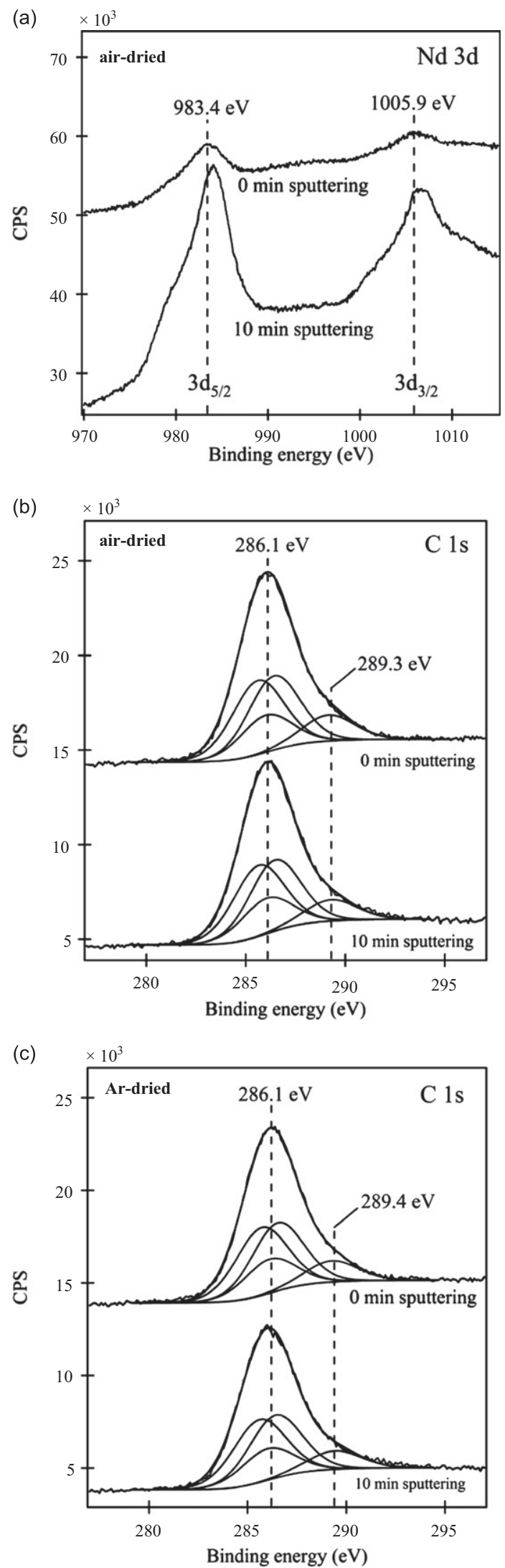

Fig. 12. XPS spectra of samples obtained after plating on Ti3 substrates using MC plating solution in pyridine: (a) Nd 3d (air-dried), (b) C 1s (air-dried), and (c) C 1s (Ar-dried) before sputtering (indicated as 0 min sputtering in the figure), and after 10 min sputtering with $\mathrm{Ar}^{+}$ions. Offsets were applied for clarity. 
(compare Fig. 12a with Figs. 10a and 11a). As shown by Fig. 12a and by the $\mathrm{C} 1 \mathrm{~s} / \mathrm{Nd} 3 \mathrm{~d}$ ratios reported in Table 4 , the intensity of the $\mathrm{Nd} 3 \mathrm{~d}$ signal increases considerably after 10 min sputtering with $\mathrm{Ar}^{+}$ions. Therefore, the produced sample is characterized by a thicker solvent layer covering the deposit compared to IP + IB and DMF. The measured binding energy of the $\mathrm{Nd} 3 \mathrm{~d}_{5 / 2}$ peak (i.e., $983.4 \mathrm{eV}$, Fig. 12a) confirms that $\mathrm{Nd}$ is deposited as $\mathrm{Nd}^{3+}$ as previously found in the case of IP + IB and DMF (possibly as carboxylate, oxide, or hydroxide). The $\mathrm{C} 1 \mathrm{~s}$ spectra reported in Figs. $12 \mathrm{~b}$ and $\mathrm{c}$ show the presence of two components, which are visible only after multicomponent fitting analysis: the components of physisorbed pyridine at ca. $286 \mathrm{eV}$, and the components of chemisorbed species at ca. $289 \mathrm{eV}$ (i.e., air: $289.3 \mathrm{eV}$, Ar: $289.4 \mathrm{eV}$ ). These higher binding energy components can be attributed to possible COOM - metal carboxylate - groups formed during the plating process. This indicates that the solvent undergoes electrolysis during the MP process and becomes oxidized. Nonetheless, the very small intensities of the chemisorbed components suggest that pyridine undergoes electrolysis only to a smaller degree than IP + IB or DMF.

Slight differences between drying in air or Ar are shown by the smaller $\mathrm{C} 1 \mathrm{~s} / \mathrm{Nd} 3 \mathrm{~d}$ ratio in air (i.e., 0.9 instead of 1.1 ), and by the larger value of the $\mathrm{C} 1 \mathrm{~s}(\mathrm{ca} .286 \mathrm{eV}) / \mathrm{Nd} 3 \mathrm{~d}$ ratio in $\mathrm{Ar}$ than in air. These differences are smaller than in the case of IP+IB and DMF. The C $1 \mathrm{~s}$ (ca. $289 \mathrm{eV}$ )/Nd 3d ratios are very similar both in air and in the Ar environment.

It has to be noticed that all the values of the ratios reported in Table 4 for the deposits prepared in pyridine are quite different from the corresponding values determined for IP + IB or DMF deposits, irrespective of the methods of sample drying. This follows from the large intensities of the $C 1 \mathrm{~s}$ signals in pyridine, as evidenced by the $C 1$ s spectra reported in Figs. $12 \mathrm{~b}$ and c, where even after 10 min sputtering the intensities of the physisorbed components are only slightly decreased.

The comparisons between the $C$ 1s spectra in Figs. 10b, c, 11b, c and $12 \mathrm{~b}, \mathrm{c}$ show no chemical shifts before and after sputtering. Small shifts of ca. $-0.5 \mathrm{eV}$ after sputtering were observed for the $\mathrm{Nd} 3 \mathrm{~d}$ spectra of the IP $+\mathrm{IB}$ and DMF samples (see Fig. 10a for IP + IB, and Fig. 11a for DMF). Shifts of ca. $+0.5 \mathrm{eV}$ after sputtering were observed for the $\mathrm{Nd} 3 \mathrm{~d}$ spectra of the pyridine samples (see Fig. 12a). This could indicate the presence of different $\mathrm{Nd}^{3+}$ species in the topmost surface layers of the samples produced from the different solvents.

From the analysis of all the obtained XPS results, the main difference which appears to occur between samples dried in air and in a controlled inert environment, such as Ar in a glove-box, is related to the higher intensities of the peaks of the physisorbed solvent components when the drying is performed in Ar. Besides this, a slightly larger amount of $\mathrm{O}$ adsorbed on the surfaces of all the samples dried in air can be noticed (see $\mathrm{O} 1 \mathrm{~s} / \mathrm{C} 1 \mathrm{~s}$ ratios in Table 4). Nonetheless, no strong indication for the presence of surface chemical reaction products promoted by the drying in air instead of Ar was found.

\subsection{Molecular plating from DMF solution}

\subsubsection{Cell potential trends}

Fig. 13 shows trends of cell potential vs. time recorded during preparation of targets, using $0.22 \mathrm{mM}\left[\mathrm{Nd}\left(\mathrm{NO}_{3}\right)_{3} \cdot 6 \mathrm{H}_{2} \mathrm{O}\right]$ solution (MC), Ti3 as deposition foil, and DMF (a) or IP + IB (b) as plating solvent. The applied constant current was $6 \mathrm{~mA}$ for $3 \mathrm{~h}$ (current density $0.7 \mathrm{~mA} / \mathrm{cm}^{2}$ ). IP $+\mathrm{IB}$ cell potential curves were already discussed in detail in [14].

From the comparison between the two cell potential curves, it is evident that after an increase at the beginning of the plating process, both curves decrease to a minimum value, then they

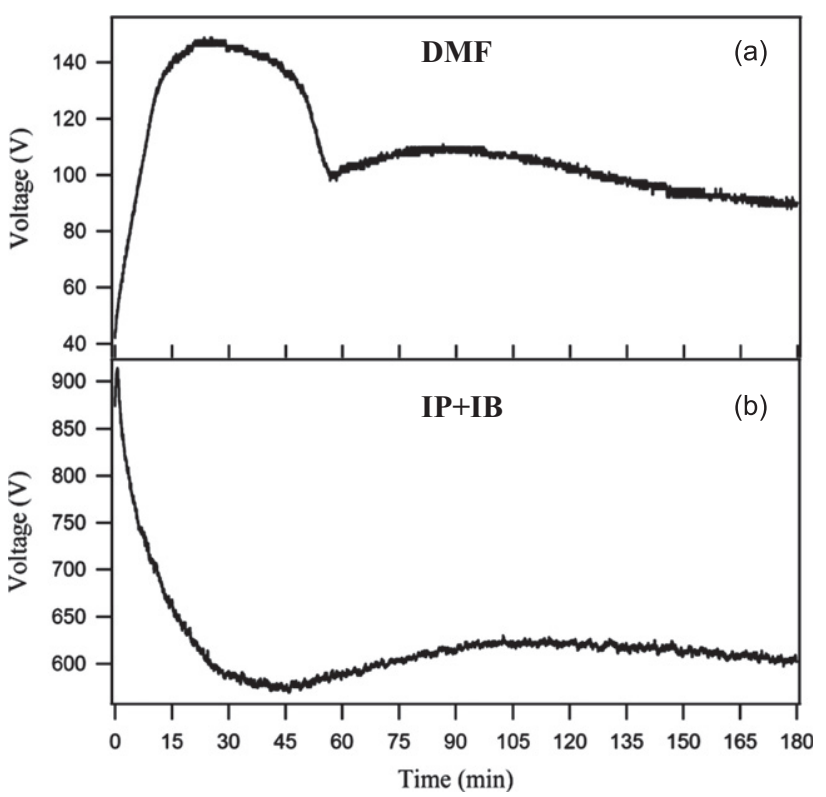

Fig. 13. Cell potential vs. time curves of molecular platings on Ti3 foils performed using MC plating solution in DMF (a) or IP $+\mathrm{IB}(\mathrm{b})$, and applying a constant current of $6 \mathrm{~mA}$ (current density $0.7 \mathrm{~mA} / \mathrm{cm}^{2}$ ).

increase again to reach a maximum. After this maximum, both cell potential curves tend to decrease slightly with time. The initial DMF cell potential increase is much bigger (ca. $100 \mathrm{~V}$ ) and lasts longer than that of IP $+\mathrm{IB}$, and forms a wide maximum after ca. $30 \mathrm{~min}$. In the case of IP + IB the increase is only a few tens of volts and it lasts only for a few minutes at the very beginning of the deposition. The cell potential drop after the initial increase is much bigger for IP+IB (ca. $350 \mathrm{~V}$ ) than for DMF (ca. $50 \mathrm{~V}$ ) and the minimum is reached earlier ( $45 \mathrm{~min}$ vs. ca. $60 \mathrm{~min}$ ). The minimum area is wider for IP+IB than for DMF. The second maximum is wide in both cases but it is achieved somewhat earlier in DMF (ca. $90 \mathrm{~min}$ ) than in IP $+\mathrm{IB}$ (ca. $110 \mathrm{~min}$ ). The cell potentials in DMF are much smaller than the values recorded in IP + IB.

\subsubsection{Kinetics derived from $\gamma$-ray spectroscopy}

The kinetics of the MP with DMF was studied by determining the Nd deposition yield values with $\gamma$-ray spectroscopy. A highpurity germanium detector (GEM series HPGe Detector Model No. GEM 23158 P-Plus, ORTEC Company), was used after MPs of MC Nd solutions containing radioactive ${ }^{147} \mathrm{Nd}$ tracer. To obtain quantitative data, reference sources with known amounts of the tracer were prepared. They consisted of filter papers with the same geometry as the targets, soaked with the tracer-containing solution. Twelve Ti3 targets were produced by electrolysis of aliquots of $100 \mu \mathrm{L}$ of this solution at different deposition times: the first target after $15 \mathrm{~min}$ and the subsequent ones after increments of $15 \mathrm{~min}$ up to $180 \mathrm{~min}$. The $\gamma$-measurements of the twelve targets gave the deposition yields reported in Fig. 14, where the dashed curve fitting the open circles shows the $\mathrm{Nd}^{3+}$ depletion trend obtained by subtracting the deposition yield from $100 \%$.

$\mathrm{Nd}^{3+}$ depletion shows an exponential decrease which can be fitted by a first-order rate law $y=y_{0} \exp (-b t)$, i.e., $[\mathrm{Nd}]_{t}=[\mathrm{Nd}]_{0} e^{-k t}$, where $[\mathrm{Nd}]_{0}$ and $[\mathrm{Nd}]_{t}$ are the initial and instantaneous concentrations of $\mathrm{Nd}^{3+}$ in solution, respectively, and $k$ is the rate constant of the process.

For comparison Fig. 14 shows also the $\mathrm{Nd}^{3+}$ depletion curve obtained during MP in IP+IB (open triangles) [14]. Both MPs follow a first-order rate law, but it is evident that the depletion kinetics is faster (i.e., $k$ is larger) in DMF than in IP+IB. In 


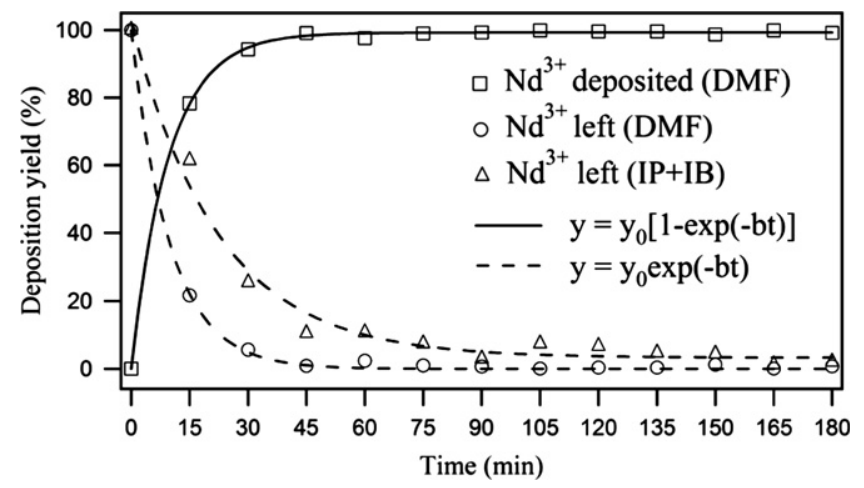

Fig. 14. Molecular platings on Ti3 foils performed using MC plating solution in DMF or IP+IB: $\mathrm{Nd}^{3+}$ deposition yield (open squares) and depletion rate (open circles) in DMF, depletion rate in IP + IB [14] (open triangles); the lines are best fittings according to a first-order growth or decay. Error bars are not shown as smaller than the size of the symbols.

particular, it is important to notice that, as in the case of IP+IB [14], the MP in DMF reaches an almost complete depletion of the $\mathrm{Nd}$ ions at a time corresponding to the recorded minimum (i.e., ca. $60 \mathrm{~min}$ ) of the cell potential curve.

\subsubsection{Conductivity measurements}

The conductivity was measured using an inoLab Cond 720 conductometer connected to a TetraCon 325 standard conductivity cell. These measurements were performed only in a stirred DMF solution containing $0.22 \mathrm{mM}\left[\mathrm{Nd}\left(\mathrm{NO}_{3}\right)_{3} \cdot 6 \mathrm{H}_{2} \mathrm{O}\right]$ and $0.3 \mathrm{mM} \mathrm{HNO}$. The conductivity $(\chi)$ was measured to be $46.5 \pm 0.1 \mu \mathrm{S} / \mathrm{cm}$. This value was used to evaluate the solution resistance, $R$, in the cell. The expression used for this evaluation is $R=\rho . l / S$ [24], where $\rho$ is the resistivity of the system (i.e., the inverse of the conductivity, $\rho=21.50 \pm 0.05 \mathrm{k} \Omega / \mathrm{cm}), l$ is the distance between the electrodes $(2.80 \pm 0.01 \mathrm{~cm})$, and $S$ is the surface area of the electrodes $(9.0$ $\pm 0.1 \mathrm{~cm}^{2}$ ). The obtained cell resistance is $6.691 \pm 0.011 \mathrm{k} \Omega$. Using Ohm's first law, $V=R I$, where $R$ is the cell resistance and $I$ is the applied current $(I=6.00 \pm 0.01 \mathrm{~mA})$, the contribution of the ohmic drop to the overall cell potential was estimated to $40.15 \pm 0.09 \mathrm{~V}$. This value is in perfect agreement with the initial experimental value in Fig. 13a. The cell potential during the MP process is, however, at least twice as high as the initial value. The voltage increase during the first $15 \mathrm{~min}$ of the electroplating is probably due to an increase of the overall resistance of the cell. Indeed, during MP the concentration of the electrolyte decreases as $\mathrm{Nd}^{3+}$ is deposited on the cathode, resulting in a decrease of conductivity. Also the formation and growth of the deposit, which is principally composed of $\mathrm{Nd}$ salts and complexes, presents an additional resistance. It appears reasonable that the cell potential observed during MPs is dominated by the ohmic drop.

\subsubsection{Temperature measurements}

Temperature measurements of the DMF plating solutions were performed using a TFK 150 thermometer connected to an inoLab $\mathrm{pH} 720 \mathrm{pH}$ meter. The temperature was measured immediately before and after $3 \mathrm{~h}$ constant current density MP experiments at $0.17,0.3$ and $1.3 \mathrm{~mA} / \mathrm{cm}^{2}$. In all cases the MP experiments started after the solutions were cooled down to $16^{\circ} \mathrm{C}$. The measurements showed temperature increases of $0.4 \pm 0.1{ }^{\circ} \mathrm{C}, 0.7 \pm 0.1{ }^{\circ} \mathrm{C}$, and 2.0 $\pm 0.1^{\circ} \mathrm{C}$, respectively. These results indicate that despite constant cooling during the experiments, a higher current density leads to a more pronounced temperature increase inside the system.

\section{Discussion}

Among various experimental parameters that may affect constant current density MP, two were found to be of crucial importance for the preparation of smooth and crack-free layers to be used as nuclear targets. These are the roughness of the deposition substrate and the solvent used for the platings. The different $\overline{R M S}$ values of the DMF MC targets grown on Ti3 and Ti5 substrates confirm that even small differences in surface roughness between the deposition substrates can influence the $\overline{R M S}$ of the growing layers [14]. Indeed, if the deposition substrate is rough (i.e., defective), the surface mobility of the deposited atoms will be reduced by trapping in the defects, and the produced layer will be of very low quality. Therefore, to produce smooth targets, deposition substrates as smooth as possible are required.

As regards the solvent, its importance does not only derive from being the medium in which the process is performed and hence the major factor influencing the electrochemistry of the MP, but also from the fact that the produced layers are mainly composed of physisorbed as well as chemisorbed solvent molecules. Hence, the role of the solvent in MP is twofold: it influences the electrochemistry of the process, but also the properties of the layer to be produced. Reasonable physical properties to be taken into account when choosing a solvent for MP are boiling point, viscosity, conductivity, and relative permittivity [16]. The boiling point determines the volatility of the solvent. The viscosity influences the rate of mass transfer in the solvent and is important in mass-transport controlled electrolytic processes like MP [14]. In turn, the rate of mass transfer influences the conductivity of the electrolyte solutions, which is fundamental for constant current density electrolysis experiments. Finally, the relative permittivity of a solvent has a decisive influence on the electrostatic solutesolute and solute-solvent interactions as well as on the dissolution and dissociation of electrolytes. In this study, pyridine and DMF were preferred over the more commonly used IP+IB mixture $[9,10]$, after a careful analysis of these physical and chemical properties. All the samples produced using IP+IB, pyridine, and DMF as plating solvents and Ti3 foils as deposition substrates showed the presence of surface cracks. The liquid AFM analysis of the IP + IB sample suggested that the drying of the layer is at the basis of the surface cracking. To rule out the possibility that cracking may be connected to eventual layer-destructive chemical surface reactions occurring during the drying in air of the samples, XPS investigations were performed. The results of these investigations give no indications for the occurrence of such reactions, as air- and Ar-dried samples presented the same XPS signals. The absence of reactivity made then possible the AFM analysis in air of all these samples. These analyses confirmed the hypothesis of the drying-related nature of cracking. Indeed, the layers presenting surface cracks after drying in air also underwent cracking in $\mathrm{Ar}$ environment. More important than the drying environment is the boiling point of the solvent. Samples prepared in solvents with low boiling point (i.e., IP+IB and pyridine) showed the most severe surface cracking and the highest roughness. In contrast, films produced in DMF on Ti3 foils showed much smaller surface cracks and roughness. The reason why solvents with lower boiling point produce layers with severe surface cracking is very likely connected to the drying process. During drying in air, removal of solvent by evaporation implies solvent diffusion to the surface, conversion at the interface from the fluid phase to the vapour phase, and finally diffusion through the boundary layer into the distant air surrounding [25]. Because solvent evaporation diminishes the volume of the stress-free state of the coating, the current state shrinks to the maximum possible extent. Ahead of the solidification front, i.e., the front indicating the transition from liquid to solid, the shrinkage produces flow in the still liquid 
coating; behind, it produces in-plane stress in the solid coating because its in-plane shrinkage is frustrated by adhesion to the substrate $[26,27]$. The difference between the current state and the stress-free state of the coating is elastic strain to which stress is proportional via the elastic modulus (i.e., $\lambda=$ stress/strain, where $\lambda$ is the elastic modulus). Experimental and theoretical investigations $[27,28]$ have shown that high elastic modulus and high yieldstress raise the level of stress and in-plane stress gradients, making the coatings susceptible to cracking and delamination. It is then reasonable to argue that because the high volatility IP + IB and pyridine solvents evaporate faster than the less volatile DMF (as we experimentally observed), the big volume decrease of the stress-free state of the coatings produced with such solvents will bring to a considerable difference between the current state and the stress-free one. The consequent large elastic modulus will then make these layers more likely to crack. In the "slow evaporation" regime achieved with DMF, instead, the difference between the states during the drying and the consequent elastic modulus will unlikely be as high as to create cracks. Cracking will mainly occur where a larger fragility of the layer is dictated by higher surface stress, i.e., where the surface defects have grown from the deposition foil. Once such defects are eliminated by using smoother deposition substrates, like Ti5, no cracks are observed in the surfaces of the produced DMF layers anymore. In particular, the layer growing on the Ti5 substrate during a MC plating experiment performed in DMF is assigned to follow a Frank-van der Merwe mechanism (layer-by-layer growth mechanism). In this growth mode a new layer is nucleated only after completion of the layer below and can spread over macroscopic distances creating very homogeneous surfaces, as demonstrated also by the RI studies.

The surface roughness and the morphology of the layers produced using DMF as plating solvent and Ti5 as deposition substrate can be considerably varied by changing some basic variables of the MP, like the concentration of the electrolyte to be plated and the applied current density. In the first case, the higher concentration of the electrolyte increases the flux of $\mathrm{Nd}^{3+}$ ions to the cathode, and hence the deposition rate onto the substrate. Because a high deposition rate causes the system to grow disorderly, the final surface roughness of the produced layer will be large [14]. In the case of the layers obtained applying different constant current densities, this simple interpretation is no longer sufficient to explain the changes observed in both roughness and morphology of the surfaces. In fact, if on the one hand, as expected, the current density of $1.3 \mathrm{~mA} / \mathrm{cm}^{2}$ increases the surface roughness of the layer produced with $0.3 \mathrm{~mA} / \mathrm{cm}^{2}$, on the other hand, the decrease to $0.17 \mathrm{~mA} / \mathrm{cm}^{2}$ increases the roughness even more. A possible explanation for these results comes from the fact that good epitaxial growths require not only low deposition rates, but also high surface mobility of the deposited species. In the case of the deposit obtained with the highest current density, the big outgrowths not covering the entire analyzed area may in fact suggest that the deposited species had a high surface mobility, which allowed them to condensate. In contrast, as regards the lowest current density sample, the rather small outgrowths spread over the entire surface area may indicate low surface mobility. The different mobilities could be related to the different temperatures of the substrates, which influence the ability of the deposited species to pass the activation barrier of diffusion. As the MP performed in DMF is controlled by Ohm's first law, the preservation of a certain constant current density for a definite period of time implies the resistance of the solution to undergo several changes. If the global trend is that of an increase in the solution resistance, the temperature of the solution may increase as well, despite thermostatation of the system. As a consequence, the temperature of the cathode may also increase. This seems to be the case, as evidenced by the temperature measurements of the DMF
MC solutions immediately before and after constant current density MPs at $0.17,0.3$ and $1.3 \mathrm{~mA} / \mathrm{cm}^{2}$. The combination of the effects of both deposition rate and surface mobility, dictated by the specific constant current density applied to the system, leads then to only few of the tested current densities being effective for defectless layer growths via MP. This is apparently the case of current densities in the range of $0.3-0.7 \mathrm{~mA} / \mathrm{cm}^{2}$.

Cell potential curves recorded during constant current density MPs in DMF showed to have common features with MPs in IP+IB [14]. As regards the initial increase of the potential at the beginning of the process and the different starting behaviours of the curves, we hypothesize that constant current density MPs, including electrolysis, create a high polarization of the electrodes, which causes the initial increase of the cell potential [14]. The smaller cell potential drop achieved with DMF than with IP+IB can be explained in terms of the larger conductivity of DMF. As both the constant current density MPs performed in IP+IB and DMF proved to be controlled by Ohm's first law, $V=R I$, it is easy to understand that the range of cell potential values must be smaller in DMF, because this solvent, having a larger conductivity, implies a smaller resistance. It is important to notice that in both solvents the deposition yield at the minimum of the cell potential curves is already high, with the depletion kinetics being faster in DMF than in IP+IB.

Finally, we like to stress that in none of the MPs performed from any of the used solvents metallic Nd was deposited. Rather $\mathrm{Nd}$ is deposited on the cathodic surfaces as $\mathrm{Nd}^{3+}$ derivatives, and this is reasonable on the basis of the highly negative value of the $\mathrm{Nd}^{3+} / \mathrm{Nd}$ standard redox potential $(E=-2.323 \mathrm{~V}$ [29]), typical of lanthanide cations.

\section{Conclusion}

To optimize the production of smooth and crack-free layers to be used as nuclear targets, several constant current density MPs were performed using $\mathrm{Nd}$ as a model element. The variables chosen for these investigations were: plating solvent, electrolyte concentration, applied current density, and surface roughness of the deposition substrate. Different environments were also used to dry the produced samples. The obtained deposits were analyzed using $\gamma$-ray spectroscopy, XPS, RI, AFM, and SEM. The results obtained from the characterization were used to identify the key parameters controlling the molecular plating of smooth and crackfree layers. The roughness of the deposition substrate and the solvent used for the platings proved to be two core factors playing a decisive role for the production of high quality layers. Surface cracking in fact occurred by means of drying only when volatile solvents and deposition substrates that were not smooth enough, were used. Different drying environments like air and Ar did not show to have any effect on the deposited layers.

Molecular platings from DMF proved to be superior over the widely performed IP + IB platings [9,10]. Indeed, despite being also governed by Ohm's first law and by similar depletion kinetics, DMF MPs performed on Ti5 substrates produced targets showing complete elimination of the surface cracks as well as high smoothness and homogeneity. Moreover, no Pd impurities from the oxidation of the Pd anode were found on the cathode deposit when MPs were performed in DMF. The absence of such impurities may be of importance in nuclear science investigations as they could give rise to unwanted background in accelerator-based experiments.

Finally, the surface roughness and morphology of the layers produced using DMF and Ti5 substrates proved to be very sensitive to changes in, e.g., electrolyte concentration and current density.

The present work demonstrates that molecular plating can be applied to produce layers that are as smooth and crack-free as those produced by PAD, and suitable as nuclear targets. An important 
advantage of MP over PAD is that it is a faster deposition process, as it needs just one plating cycle to reach almost $100 \%$ deposition yield. With PAD, in contrast, coating efficiencies for one single application of ca. $33 \%$ are reported [11]; hence several deposition cycles need to be performed to obtain quantitative yields.

The results obtained in this study may also be applied for the production of smooth and crack-free lanthanide targets other than $\mathrm{Nd}$, and also for the preparation of heavier actinide targets with an oxidation state of $3+$ (e.g., americium and curium), for which $\mathrm{Nd}$ is a good model element.

\section{Acknowledgements}

The authors would like to thank the staff of the TRIGA Mainz for performing the irradiations and Dr. T. Lauer for performing the coating of the $\mathrm{Si}$ wafers. A. Vascon would like to thank V. Yakusheva from the GSI target laboratory for her assistance during the SEM measurements and acknowledges financial support from the German Federal Ministry of Science and Education (BMBF) under Contract number 02NUK013E.

\section{References}

[1] A. Becerril-Vilchis, A. Cortès, F. Dayras, J. De Sanoit, Nuclear Instruments and Methods in Physics Research Section A: Accelerators, Spectrometers, Detectors and Associated Equipment 369 (1996) 613.

[2] B.W. Filippone, M. Wahlgren, Nuclear Instruments and Methods in Physics Research Section A: Accelerators, Spectrometers, Detectors and Associated Equipment 243 (1986) 41

[3] K.M. Glover, L. Bint, D.B. Gayther, M. King, B. Whittaker, R.A.P. Wiltshire, Nuclear Instruments and Methods 200 (1982) 151

[4] S. Clifford, X. Guo-jj, C. Ingelbrecht, M.J. Pomeroy, Nuclear Instruments and Methods in Physics Research Section A: Accelerators, Spectrometers, Detectors and Associated Equipment 480 (2002) 29.

[5] R. Grossmann, H.J. Maier, H.U. Friebel, D. Frischke, Nuclear Instruments and Methods in Physics Research Section A: Accelerators, Spectrometers, Detectors and Associated Equipment 480 (2002) 209.

[6] L.V. Drapchinsky, T.E. Kuzmina, S.M. Soloviev, Nuclear Instruments and Methods in Physics Research Section A: Accelerators, Spectrometers, Detectors and Associated Equipment 438 (1999) 116

[7] S. Chakrabarty, B.S. Tomar, A. Goswami, V.A. Raman, S.B. Manohar, Nuclear Instruments and Methods in Physics Research Section B: Beam Interactions with Materials and Atoms 174 (2001) 212

[8] K.M. Glover, F.J.G. Rogers, T.A. Tuplin, Nuclear Instruments and Methods 102 (1972) 443.
[9] N. Trautmann, H. Folger, Nuclear Instruments and Methods in Physics Research Section A: Accelerators, Spectrometers, Detectors and Associated Equipment 282 (1989) 102

[10] K. Eberhardt, M. Schädel, E. Schimpf, P. Thörle, N. Trautmann, Nuclear Instruments and Methods in Physics Research Section A: Accelerators, Spectrometers, Detectors and Associated Equipment 521 (2004) 208.

[11] M.A. Garcia, M.N. Ali, T. Parsons-Moss, P.D. Ashby, H. Nitsche, Thin Solid Films 516 (2008) 6261

[12] M.A. Garcia, M.N. Ali, N.N. Chang, T. Parsons-Moss, P.D. Ashby, J.M. Gates, L. Stavsetra, K.E. Gregorich, H. Nitsche, Nuclear Instruments and Methods in Physics Research Section A: Accelerators, Spectrometers, Detectors and Associated Equipment 592 (2008) 483.

[13] Q.X. Jia, T.M. McCleskey, A.K. Burrell, Y. Lin, G.E. Collis, H. Wang, A.D.Q. Li, S.R. Foltyn, Nature Materials 3 (2004) 529.

[14] A. Vascon, S. Santi, A.A. Isse, T. Reich, J. Drebert, H. Christ, E. Düllmann, K. Eberhardt, Nuclear Instruments and Methods in Physics Research Section A: Accelerators, Spectrometers, Detectors and Associated Equipment 696 (2012) 180.

[15] A. Vascon, E. Düllmann, K. Eberhardt, B. Kindler, B. Lommel, J. Runke, Nuclear Instruments and Methods in Physics Research Section A: Accelerators, Spectrometers, Detectors and Associated Equipment 655 (2011) 72.

[16] K. Izutsu, Electrochemistry in Nonacqueous Solutions, first ed., Wiley-VCH, Darmstadt, Germany, 2002.

[17] A. Vascon, S. Santi, A.A. Isse, T. Reich, J. Drebert, H. Christ, K. Eberhardt, E. Düllmann, Journal of Radioanalytical and Nuclear Chemistry (2012), accepted.

[18] R. Horcas, J.M. Fernandez, J. Gomez-Rodriguez, J. Colchero, A.M. GomezHerrero, W. Baro, Review of Scientific Instruments 78 (2007) 013705.

[19] D. Liebe, K. Eberhardt, W. Hartmann, T. Häger, A. Hübner, J.V. Kratz, B. Kindler, B. Lommel, P. Thörle, M. Schädel, J. Steiner, Nuclear Instruments and Methods in Physics Research Section A: Accelerators, Spectrometers, Detectors and Associated Equipment 590 (2008) 145.

[20] U. Gelius, P.F. Hedèn, J. Hedman, B.J. Lindberg, R. Manne, R. Nordberg, C. Nordling, K. Siegbahn, Physica Scripta 2 (1970) 70.

[21] R.C. Gray, J.C. Carver, D.M. Hercules, Journal of Electron Spectroscopy and Related Phenomena 8 (1976) 343.

[22] D.T. Clark, R.D. Chambers, D. Kilcast, W.K.R. Musgrave, Journal of the Chemical Society, Faraday Transactions 2 (68) (1972) 309.

[23] C.D. Wagner, W.M. Riggs, L.E. Davis, J.F. Moulder, G.E. Muilenberg, Handbook of X-Ray Photoelectron Spectroscopy, 55344, Perkin-Elmer Corporation, Eden Prairie, Minn, 1979, Physical Electronics Division.

[24] S. Glasstone, An Introduction to Eletrochemistry, first ed., Litton Educational Publishing, Inc., New York, 1942.

[25] D.E. Haas, J.N. Quijada, S.J. Picone, D.P. Birnie, in: B. Dunn, E. Pope, H.K. Schmidt, M. Yamane, (Eds.), SPIE Proceedings, Sol-Gel Optics V, 3943 (2000) 280-284.

[26] H. Lei, L.F. Francis, W.W. Gerberich, L.E. Scriven, AIChE Journal 48 (2002) 437.

[27] H. Radhakrishnan, Ph.D. Thesis, University of Minnesota, Minneapolis, MN, USA, 2006.

[28] J. Malzbender, G. De With, Journal of Materials Science 35 (2000) 4809

[29] D.R. Lide (Ed.), CRC Handbook of Chemistry and Physics, 87th ed., 2006. 